\title{
Financial Fragility in Small Open Economies: Firm Balance Sheets and the Sectoral Structure
}

\author{
Y. KALANTZIS \\ Banque de France
}

First version received August 2007; final version accepted January 2015 (Eds.)

\begin{abstract}
Episodes of large capital inflows in small open economies are often associated with a shift of resources from the tradable to the non-tradable sector and sometimes lead to balance-of-payments crises. This article builds a two-sector dynamic model to study the evolution of the sectoral structure and its impact on financial fragility. The model embeds a static mechanism of balance-of-payments crisis which produces multiple equilibria within a single time period when the non-tradable sector is large enough compared to the tradable sector. The article studies the dynamics induced by an increase in financial openness. It shows that the relative size of the non-tradable sector overshoots, which makes the economy more likely to be financially fragile during the transitory dynamics. Using an extended version of the model, the article conducts a quantitative analysis and shows that this mechanism accounts well for several episodes of large capital inflows that led to financial crises.
\end{abstract}

Key words: Two-sector models, capital account liberalization, balance-of-payments crises, foreign currency debt, borrowing constraint, euro area crisis

JEL Codes: E44, F32, F34, F43, O41

\section{INTRODUCTION}

Capital inflows can have substantial effects on the sectoral allocation of resources. The opening of developing economies to foreign capital flows in the last three decades was followed in a number of cases by a shift of resources from the tradable to the non-tradable sector. The same phenomenon took place in the periphery countries of the euro area as they joined the currency union and fully integrated their interbank markets. As documented below, in the first few years of such episodes of capital inflows, the size of the non-tradable sector, relative to that of the tradable sector, increased on average by about $4 \%$ above normal times. During the same period many economies experienced financial and balance-of-payments crises. In addition to the different factors of fragility identified by the empirical literature, sectoral factors also seemed to have played a role. As documented below, crises took place in countries and in times where the nontradable sector was larger than usual compared to the tradable sector. It is tempting to see a link between these two facts. Do episodes of large capital inflows lead to financial fragility through the channel of sectoral change? 
(a) Event study of large capital inflows

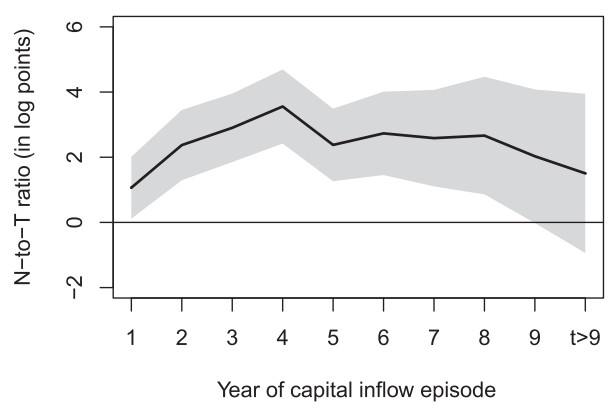

(b) Logit model of twin crises

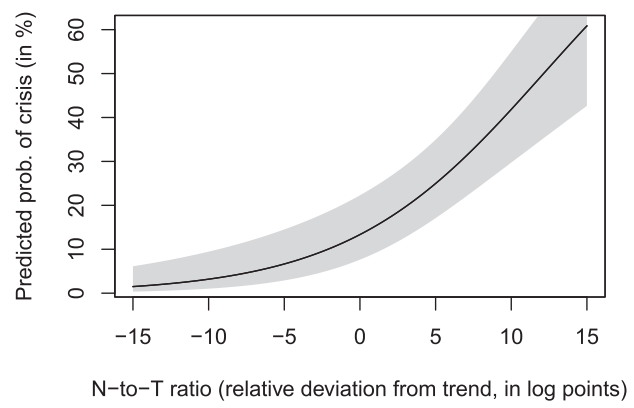

FIGURE 1

(a) Evolution of the N-to-T ratio during an episode of large capital inflows. Horizontal axis: time dummies indicating the number of years since the start of the episode. The solid line plots point estimates (in log points) in a panel regression of the N-to-T ratio on the time dummies. (b) Predicted probability of a twin crisis in the coming three years as a function of the (detrended) $\mathrm{N}$-to-T ratio, for an emerging economy, keeping other variables at their mean three years before a crisis. Shaded areas represent $95 \%$ confidence bands

The article presents a framework to address this question. It builds a two-sector dynamic model of a small open economy where balance-of-payments crises can happen within single time periods. The model shows that an increase in financial openness resulting in capital inflows is followed by an increase in the relative size of the non-tradable sector, and that this change in the sectoral structure can make crises possible.

The article starts by documenting two stylized facts related to capital flows, sectoral dynamics, and financial fragility. First, the size of the non-tradable sector relative to that of the tradable sector-the non-tradable to tradable (N-to-T) ratio-increases above its trend in the first few years of an episode of large capital inflows. Figure 1a summarizes an event study using yearly data on 40 countries between 1970 and 2010. In this sample, 47 episodes of large capital inflows are identified. The figure shows the result of a panel regression of the $\mathrm{N}$-to-T ratio on time dummies indicating the number of years since the beginning of the episode. The relative deviation of the $\mathrm{N}$-to-T ratio from its trend is found to peak at about $4 \%$ after four years. This dynamics holds for both emerging and advanced economies, including periphery countries of the euro area, and for both pegs and floating exchange rates.

Second, the relative size of the non-tradable sector is a good predictor of twin crises, defined as the joint occurrence of sudden stops and banking crises. There are 21 such crises in the sample. Using a discrete-choice model, the probability that a twin crisis will take place within the next three years is found to be positively correlated with the relative deviation of the N-to-T ratio from its trend, with a coefficient both statistically and economically significant. Figure $1 \mathrm{~b}$ shows how the predicted probability of crisis substantially increases with the N-to-T ratio in an emerging economy, keeping other variables at their mean three years before a crisis.

To reproduce these two stylized facts, the article embeds a static model of self-fulfilling balance-sheet crisis into a dynamic two-sector model. A key feature of the dynamic model is the slow reallocation of factors between sectors. First, production takes time, which prevents sectoral reallocation of resources within a single time period. Second, firms operate with decreasing returns to scale, which deters entrepreneurs from increasing production too quickly. Another important feature is the fact that production of both goods requires non-tradable goods as an input. With those assumptions, an increase in financial openness (modelled as a permanently lower real interest rate) leads to a persistent overshooting of the real exchange rate and the N-to-T ratio. Intuitively, a lower 
interest rate increases the desired scale of production in both sectors and therefore the demand for non-tradable inputs. With predetermined supply, the relative price of non-tradable goods-the real exchange rate-initially appreciates. Because of decreasing returns to scale, it is not optimal for the non-tradable sector to expand quickly, which makes this overshooting persistent. Since the relative marginal productivity of inputs in both sectors depends on the relative price of the non-tradable good, the N-to-T ratio follows a similar dynamics, with a persistent increase above its steady state value.

This dynamics can be interrupted by self-fulfilling crises, modelled as in Krugman (1999), Aghion et al. (2004), and Schneider and Tornell (2004). As in these papers, the crisis mechanism relies on two frictions: borrowing constraints and the absence of a market for bonds denominated in non-tradable goods. The latter gives rise to a currency mismatch in the non-tradable sector. With these two frictions, there can be a second within-period equilibrium, corresponding to a crisis, in addition to the normal time equilibrium. This crisis equilibrium is shown to only exist when the non-tradable sector is large enough in relative terms. This implies that crises are more likely to take place in the medium run after an increase in financial integration, when the N-to-T ratio is large. The intuition is the following. In a crisis equilibrium, binding borrowing constraints limit the demand for non-tradables, which reduces their relative price-the real exchange rate depreciates. The larger the supply of non-tradables, the lower their relative price. Because of the currency mismatch, this hurts the balance sheet of the non-tradable sector. With a sufficiently large supply of non-tradables, this balance-sheet effect is strong enough to make borrowing constraints bind in the first place, yielding a self-fulfilling crisis. In the model, the two financial frictions are only important in times of crisis: the analysis of the no-crisis dynamics is carried out with the assumption that the borrowing constraint does not bind, which makes balance-sheet variables and currency mismatches irrelevant in normal times.

Those results are first derived analytically in a simple version of the model. The model is then extended to a more realistic set-up to conduct a quantitative analysis and shed light on several known episodes of large capital inflows that led to twin crises. These episodes cover four waves of large financial crises: the Nordic crises of the late eighties, the Asian crisis of 1997, crises in Latin America in the late nineties, and recent crises at the periphery of the euro area. Using Bayesian methods, I decompose the observed dynamics of GDP, the current account, and the N-to-T ratio during those episodes into movements of a financial transaction cost and two productivity shocks. The observed current account and sectoral dynamics are found to be largely driven by a decrease in the financial transaction cost, which in the model corresponds to financial integration. Then, the implication for financial fragility and crises is worked out, focusing on the example of Thailand in the nineties. I look at the impact on financial fragility of the lower cost of financing backed out from the data. Financial fragility is found to be more likely to obtain during the transition to the new steady state, supporting the theoretical finding of the simple model. I also show that the model matches the behaviour of several key variables during the crisis, in particular the real exchange rate, investment, and employment.

A key innovation of this article is to connect the literature studying the sectoral evolution of open economies to the literature on emerging market crises. While the crisis literature has extensively studied mechanisms at play during crises, little is known about the dynamics that precedes those events. On the other hand, a long tradition in international macroeconomics has tried to explain sectoral change in two-sector open economies, but these works have not explored the implications for financial fragility. In this article, I show how an episode of capital inflows triggered by financial liberalization endogenously leads to a build-up of financial fragility through the channel of sectoral change. This link between financial liberalization, precrisis sectoral dynamics, and crisis times offers a new perspective compared to the existing literature. 
The article also contributes to the empirical literature by documenting the link between capital inflows, the sectoral allocation of resources, and crises. To the best of my knowledge, this empirical evidence is novel. It suggests that sectoral dynamics were important both for emerging market crises of the past decades and for the more recent crises in the periphery of the euro area, thus contributing to a better understanding of those events.

As regards the literature on sectoral dynamics, several works studied how the discovery of natural resources affects the allocation of resources between the tradable and the non-tradable sectors, the so-called Dutch disease. The reader may for example refer to Corden and Neary (1982), Bruno and Sachs (1982), and van Wijnbergen (1984). In the present article, the shift of resources towards the non-tradable sector is triggered instead by a permanent decrease in the domestic interest rate resulting from financial integration, as in de Cordoba and Kehoe (2000) who study the effect of capital account liberalization in Spain with a two-sector model. In contrast, Benigno and Fornaro (2014) study a consumption boom triggered by a temporarily lower interest rate in a model with perfect factor mobility across sectors. The resulting sectoral dynamics is simply driven by the transitory consumption boom. Because of increasing returns in the tradable sector, this dynamics is inefficient, but it does not lead to a severe financial crisis as in the present article. Similarly, Caballero and Lorenzoni (2007) study the optimal policy response to episodes of temporary but persistent appreciations which, together with a financial friction, move resources away from the export sector to the non-tradable sector.

An alternative candidate for the shock triggering the sectoral dynamics could be the exchange rate-based stabilization plans that were implemented in several developing countries. ${ }^{1}$ These plans consisted in stabilizing inflation by anchoring the domestic currency through an exchangerate peg. Several papers have shown, both empirically and theoretically, that they have led to real appreciations and current account deficits. The effect of the reform is generally equivalent to a decrease of the domestic real rate of interest and plays the same role as financial integration in my model. ${ }^{2}$ Interestingly, the idea that there could be "possible links between the dynamics of exchange rate-based stabilizations and balance-of-payments crises" has been mentioned (Calvo and Vegh, 1999, p. 1535) but has not been studied formally, and no clear mechanism has been identified. This article provides such a mechanism. Another difference is that the literature on stabilization episodes has focused on real exchange rate dynamics, not on sectoral dynamics as the present article does. While some works hint at the initial boom in non-tradables (Rebelo and Vegh, 1995, footnote 3), it has not been empirically documented. Several papers use two-sector models to quantitatively reproduce observed real exchange rate movements (Rebelo and Vegh, 1995; Uribe, 1997; Burstein et al., 2003) but do not compare the resulting dynamics of the N-to-T ratio with the data. In addition, the sectoral reallocation observed in the data is still present in a subsample that excludes capital inflow episodes coinciding with known stabilization plans, calling for a more general explanation.

The existing literature using two-sector models has long recognized the need to assume some restriction to factor mobility in order to get realistic dynamics. For instance, Rebelo and Vegh (1995) assume a fixed factor of production in the non-tradable sector (land) and adjustment costs to capital in the tradable sector; Uribe (1997) assumes adjustment costs and gestation lags in the accumulation of sector-specific capital; and de Cordoba and Kehoe (2000) assume adjustment

1. I am grateful to Pierre-Olivier Gourinchas and an anonymous referee for suggesting this.

2. See Rebelo and Vegh (1995) and Calvo and Vegh (1999) for a review. The main mechanisms proposed by the literature have been inflation inertia, which temporarily decreases the real rate of interest, and the lack of credibility of the reform, which induces a consumption boom as households expect a temporary decrease in the opportunity cost of holding money for transactions. In Rebelo and Vegh (1995), Uribe (1997), and Burstein et al. (2003), inflation acts as a tax on transactions and creates a wedge between the return on capital and the foreign interest rate. 
frictions for both capital and labour at the sectoral level. In the present article, the assumption that production is decided one period in advance and that firms operate with decreasing returns to scale plays a similar role. It produces a persistent overshooting of the N-to-T ratio without having to resort to adjustment costs. An appealing feature of this assumption is that decreasing returns to scale have empirical support from firm-level evidence, which can be used in a calibration exercise, whereas there is a large uncertainty on parameters governing adjustment costs.

The article also borrows ingredients from the literature on balance-of-payments crises: namely borrowing constraints and currency mismatches. The interplay between those two ingredients gives rise to a balance-sheet effect in the corporate sector, which has been shown to generate multiple equilibria (Krugman, 1999; Aghion et al., 2004; Schneider and Tornell, 2004), amplify otherwise small shocks (Mendoza, 2002), and lead to inefficient overborrowing ex ante (Bianchi, 2011). I follow the former set of papers closely. Most of this literature is primarily concerned with modelling the crisis itself and discussing policy options but not with understanding the dynamics that possibly leads to it. An exception is Schneider and Tornell (2004) who study the growth of the non-tradable sector during a transitory lending boom and show that a large enough boom can lead to a self-fulfilling crisis. I follow their methodology of inserting a static crisis mechanism into a dynamic framework, but my paper differs substantially from theirs in important ways. First, they focus on the non-tradable sector alone while I study the allocation of resources between the tradable and the non-tradable sectors, which are therefore modelled explicitly and in a symmetric way. Second, their dynamics of non-tradables is driven by a binding borrowing constraint which, together with a linear technology, leads to the cumulative growth of internal funds, investment, and the price of non-tradables. ${ }^{3}$ In the present article, on the contrary, the mechanism of sectoral reallocation does not rely on financial frictions: since borrowing constraints do not bind in normal times, the pre-crisis dynamics reduces to a standard neoclassical two-sector model. This is appealing given that the sectoral reallocation is observed in both emerging and advanced economies, as I document below, whereas binding borrowing constraints are more likely to be a feature of emerging economies with underdeveloped financial markets. In addition, leverage, an important variable to determine financial fragility, is endogenous and not pinned down by the borrowing constraint: this allows me to distinguish the effect of a larger non-tradable sector (with respect to the tradable sector) from that of a more indebted non-tradable sector, in line with the empirical evidence which shows that both credit and the N-to-T ratio are good predictors of crises. Third, while their model has a finite number of periods, the present article considers an infinite time horizon, which makes it possible to study the effect of financial openness both during the transitory phase of sectoral change and in the new steady state. Finally, their model focuses on the theoretical mechanisms while I also conduct a quantitative analysis.

The link between crisis time and pre-crisis dynamics has been recently studied in another context - the real estate boom and bust in the U.S. - by Mian and Sufi (2009, 2010). Using crosssectional regional data, they show how the strength of the 2007-2009 recession is related to increases in household leverage in previous years, and provide suggestive evidence that the expansion in mortgage credit might be due to a positive credit supply shock. In my analysis, leverage also plays a role, as shown both by the empirical evidence and the theoretical results, and financial integration in the model is equivalent to a positive credit supply shock. Complementary to leverage, I stress the importance of sectoral reallocation as a key factor of fragility to twin crises. Whether sectoral factors have played a similar role in the U.S. housing boom is an open question: according to Mian and Sufi's (2010) results, there is no clear correlation between the strength of the recession and sectoral shares of employment at the onset of the bust. However,

3. This requires a high enough expected future price of non-tradables, induced for example by a reform that is believed to increase the future demand for non-tradable goods. 
sectoral asymmetries during the bust have been documented (Mian and Sufi, 2014) and can be accounted for by quantitative models (Philippon and Midrigan, 2011; Kehoe et al., 2014). These models rely on a borrowing constraint which depends on the price of housing. This plays a role similar to the borrowing constraint depending on the real exchange rate used in my article, which I borrow from the literature on balance-of-payments crises cited above.

The article is organized as follows. Section 2 documents the two stylized facts. A simple version of the model is presented in Section 3. Section 4 extends the model to a more realistic set-up and uses it to shed light on several historical episodes of large capital inflows leading to twin crises. Section 5 concludes.

\section{EMPIRICAL EVIDENCE}

This section documents the two empirical facts mentioned in the introduction: sectoral dynamics during episodes of large capital inflows and the link between the sectoral structure and the crises.

I use yearly data for 40 countries ( 24 emerging and 16 advanced economies) covering the period 1970-2010. The sample has 47 episodes of large capital inflows defined by a large and persistent drop in the current account. The average duration of an episode is eight years. Many episodes coincide with known financial or capital account liberalizations, e.g. in the Southern cone countries in the nineteen-seventies, the Nordic countries in the late nineteen-eighties, or Latin American and Asian countries in the nineteen-nineties. ${ }^{4}$ More recently, the creation of the euro area, which resulted in the full integration of interbank markets, was also associated with several episodes in periphery countries.

The sample also include 21 twin crises, defined as events featuring simultaneously a sudden stop and a banking crisis. Out of those, 15 take place at the end of an episode of capital inflows: almost a third of capital inflows episodes finish with a crisis. Most of the well-known twin crises are captured by the definition: the Nordic crises of the early nineteen-nineties, the Asian crisis, the Mexican and Argentinean crises, as well as the recent crises of the euro area periphery.

For additional explanations on those definitions and a description of the data and methodologies used, refer to Kalantzis (2014), a more detailed working paper version of this article.

\subsection{Sectoral dynamics during episodes of large capital inflows}

The first empirical fact that motivates the article is illustrated by Figure 1a. The figure summarizes an event study using the data described above. The logarithm of the non-tradable to tradable ratio (measured in constant price value added) is regressed on time dummies indicating the number of years since the beginning of the episode, followed by a dummy indicating all remaining years of the episode. The panel regression uses a GLS estimator to allow for country-specific heteroskedasticity and autocorrelation, controls for a linear time trend interacted with country dummies and for the occurrence of twin crises. ${ }^{5}$ The non-tradable to tradable ratio is found to increase above its trend at the beginning of the episode, peaking at about $4 \%$ after four years.

Figure 2 reports robustness checks obtained by splitting the set of episodes in different subsets. It shows that the N-to-T ratio increases in both advanced and emerging countries (Figure $2 \mathrm{a}$ and $\mathrm{b}$ ), with either pegged or floating exchange rates (Figure 2e and f). Episodes

4. See Kaminsky and Schmukler (2003) for de jure indices of liberalization.

5. Tornell and Westermann (2002) find that the production of non-tradable goods falls with respect to that of tradable goods during twin crises. 
(a) Advanced economies

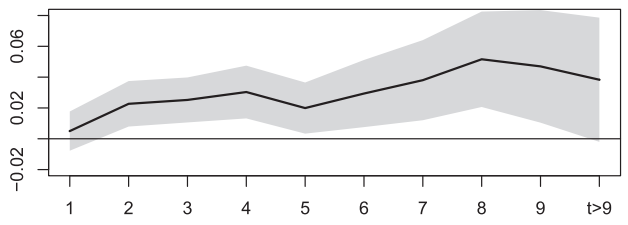

(c) Non-euro area economies

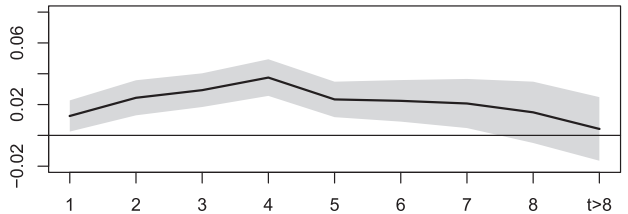

(e) Floating countries

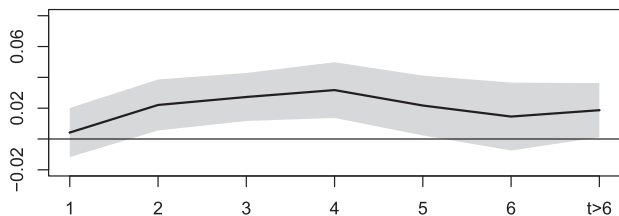

(g) FX-based stabilization episodes

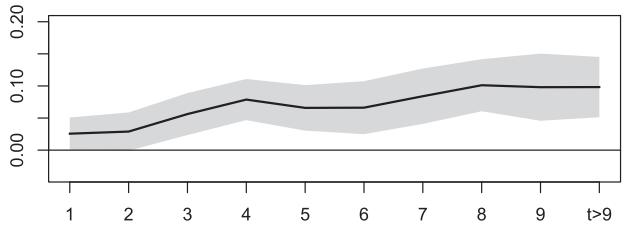

(b) Emerging economies

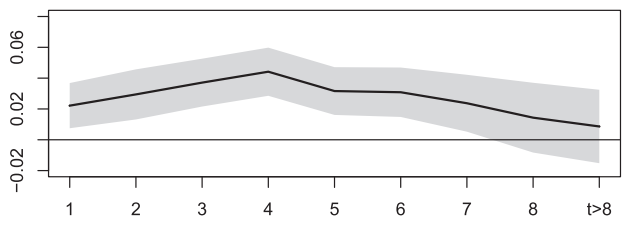

(d) Euro area economies

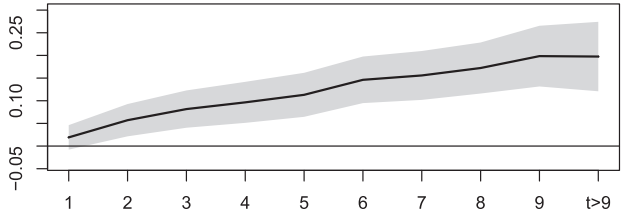

(f) Pegged countries

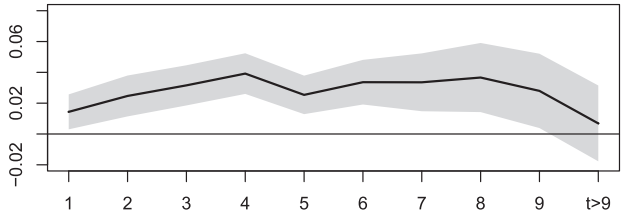

(h) Other episodes

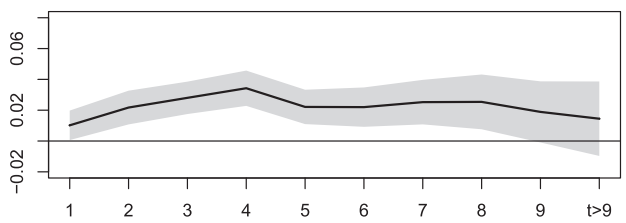

FIGURE 2

Evolution of the N-to-T ratio during an episode of large capital inflows. Horizontal axis: time dummies indicating the number of years since the start of the episode. The solid line plots point estimates (in log) in a panel regression of the N-to-T ratio on the time dummies. The shaded area represents the 95\% confidence interval. See Kalantzis (2014) for details

corresponding to the creation of the euro are particularly strong and long-lasting, and were not over yet in 2007, the latest year of sectoral data in the sample (Figure 2d). Figure $2 \mathrm{~g}$ and $\mathrm{h}$ isolate episodes coinciding with exchange rate-based stabilization plans. There are four such episodes in the sample. ${ }^{6}$ As explained in the introduction, these stabilization plans could be an alternative explanation for the non-tradable boom. Indeed, Figure $2 \mathrm{~g}$ shows a large and sustained increase of the N-to-T ratio in those episodes. However, the stylized fact stays valid for the remaining episodes, suggesting that this sectoral dynamics is driven by a more general mechanism. 
TABLE 1

Logit model of the probability of a twin crisis

\begin{tabular}{lccc}
\hline & $(1)$ & $(2)$ & $(3)$ \\
\hline N-to-T ratio & & $15.4^{* * *}$ & $15.7^{* * *}$ \\
& & $(3.3)$ & $(3.4)$ \\
Relative price N/T & $3.9^{*}$ & $4.0^{*}$ \\
& & $(2.2)$ & $(2.3)$ \\
Current account & $-14.7^{* * *}$ & $-12.6^{* * *}$ & $-12.6^{* * *}$ \\
& $(4.0)$ & $(4.3)$ & $(4.3)$ \\
Credit/GDP & $9.7^{* * *}$ & $6.8^{* * *}$ & $6.8^{* * *}$ \\
& $(1.3)$ & $(1.5)$ & $(1.5)$ \\
GDP growth & 3.1 & 3.6 & $(.2$ \\
REER & $(5.4)$ & $(5.8)$ & $(6.0)$ \\
& 0.7 & -0.5 & $(1.2)$ \\
Reserves/GDP & $(1.1)$ & $(1.2)$ & $-8.0^{* * *}$ \\
& $-10.4^{* * *}$ & $-7.9^{* *}$ & $(3.1)$ \\
Emerging country & $(3.2)$ & $(3.1)$ & $\left(1.9^{* * *}\right.$ \\
& $1.9^{* * *}$ & $1.9^{* * *}$ & $(0.5)$ \\
FX peg & $(0.5)$ & $(0.5)$ & -0.2 \\
& & & $(0.4)$ \\
\hline$N$ & & & 40 \\
$N \times T$ & 40 & 40 & 894 \\
\hline
\end{tabular}

Notes: Dependent variable: probability that a twin crisis takes place in a three-year window. The N-to-T ratio, the relative price of non-tradables, and the real effective exchange rate (REER) are in logarithm. All three variables and credit/GDP are deviations from a linear trend. Standard errors are reported in parenthesis. ${ }^{* * *} p<0.01,{ }^{* *} p<0.05,{ }^{*} p<0.1$.

\subsection{Sectoral structure and twin crises}

To document the role of sectoral factors in twin crises, I estimate a discrete-choice logit model of crisis, in the tradition of the early-warning literature. Results are displayed in Table 1 . The dependent variable is the probability that a twin crisis occurs within a three-year window. Column (1) reports results for a standard model using the current account, private credit, GDP growth, the real effective exchange rate, reserves and an emerging economy dummy as predictors of crisis. The probability of twin crises is higher when current account deficits are large and private credit is booming, and crises are more likely in emerging economies.

Column (2) complements this model with sectoral variables: the (detrented) N-to-T ratio and the (detrended) relative price of non-tradables. The $\mathrm{N}$-to-T ratio is statistically significant at the $1 \%$ level with a positive sign: a larger $\mathrm{N}$-to-T ratio is associated with a higher probability of future crisis. In Kalantzis (2014), I show that these results are robust to controlling for many factors. This is the case, for example, of the exchange rate regime, which does not seem to be correlated with the probability of crisis as shown in Column (3).

To get a sense of the economic importance of the N-to-T ratio, set all other variables at their mean value three years before a crisis. In an emerging economy, according to the model estimated in Column (2) of Table 1, the probability that a twin crisis takes place within the next three years would increase from $13 \%$ to $42 \%$ when the N-to-T ratio increases from its trend to $10 \%$ above its trend. Figure $1 \mathrm{~b}$ illustrates this result.

Table 2 reports the result of a counterfactual exercise for a set of selected twin crises using the benchmark model described above. I compute the probability of a crisis in the coming three years that would have prevailed if the $\mathrm{N}$-to- $\mathrm{T}$ ratio had been at its trend instead of being high above its trend. As the table makes clear, according to the model, probabilities of a twin crisis would have been substantially lower without the boom in non-tradables. 
TABLE 2

Counterfactual probability of crises without the $N$-to-T boom

\begin{tabular}{lcccc}
\hline Country & Year & N-to-T & Predicted & Counterfactual \\
\hline $\begin{array}{l}\text { Nordic crisis } \\
\text { Finland }\end{array}$ & 1992 & 0.11 & & \\
Sweden & 1993 & 0.14 & 0.13 & 0.03 \\
$\begin{array}{l}\text { Asian crisis } \\
\text { Malaysia }\end{array}$ & 1998 & 0.06 & 0.20 & \\
Thailand & 1997 & 0.15 & 0.43 & 0.22 \\
Latin America & & & 0.78 & \\
Argentina & 2001 & 0.05 & 0.25 & 0.14 \\
Colombia & 1999 & 0.07 & 0.19 & 0.08 \\
$\begin{array}{l}\text { Euro area crisis } \\
\text { Spain }\end{array}$ & & & & 0.09 \\
Greece & 2009 & 0.16 & 0.52 & 0.12 \\
\hline
\end{tabular}

Notes: Counterfactual exercise for selected twin crises. The third column reports the N-to-T ratio three-years before the event (log deviation from trend). The fourth column reports the predicted probability of crisis three-years before the event using the model of Table 1, Column (2). The fifth column reports the counterfactual probability of crisis had the N-to-T ratio been at its trend.

Those results are consistent with Tornell and Westermann (2002) who show that the relative size of the non-tradable sector usually increases before twin crises in middle-income countries. Calvo et al. (2004) also find that the probability of a sudden stop is higher in economies where the production of tradable goods is small compared to the pre-crisis current-account deficit, a variable that partly captures the sectoral structure.

\section{A SIMPLE FRAMEWORK}

This section considers a simple framework with no labour, no capital, and where the non-tradable good is only used as an intermediate input. This makes it possible to solve the model analytically and to study the mechanism of sectoral reallocation in a transparent way. These assumptions will be relaxed in Section 4 which studies a more realistic setup where production also requires the use of capital and labour, and the non-tradable good enters in the composition of consumption, investment, and intermediate goods.

\subsection{The set-up}

Consider a small open economy. Time is discrete. There are two types of goods: a tradable good T and a non-tradable good N. The tradable good T is chosen as the numeraire. Denote $p_{t}$ the relative price of the non-tradable good in period $t$. The relative price $p_{t}$ is a measure of the real exchange rate. A high value of $p_{t}$ corresponds to an appreciated real exchange rate.

3.1.1. Production. The tradable good $\mathrm{T}$ is produced by a tradable sector (sector $\mathrm{T}$ ). It can also be imported and any excess production of tradable goods can be exported. The nontradable good $\mathrm{N}$ is exclusively produced by a domestic non-tradable sector (sector $\mathrm{N}$ ) and the whole production has to be used domestically.

Each sector is composed of a continuum of firms of measure one. Production uses an intermediate input $\mathrm{Z}$ with decreasing returns to scale. Inputs have to be purchased one period before production can be sold. A firm in sector $s$ buys a quantity $z_{t+1}^{s}$ of inputs in period $t$ and produces a quantity $\left(z_{t+1}^{s}\right)^{\theta}$ sold in period $t+1$, where $\theta \in(0,1)$ measures returns to scale. 
The intermediate good $\mathrm{Z}$ itself is produced by a competitive intermediate sector with a CobbDouglas production function: $y_{t}^{Z}=\left(\frac{x_{t}^{T}}{1-\mu}\right)^{1-\mu}\left(\frac{x_{t}^{N}}{\mu}\right)^{\mu}$, where $x_{t}^{T}\left(x_{t}^{N}\right)$ is the input of tradables (non-tradables) used in the production of intermediate goods $Z$. Denote $p^{Z}$ the price of good $Z$.

3.1.2. Agents. There are three kinds of agents: entrepreneurs, foreign lenders, and intermediate firms. Entrepreneurs and foreign lenders derive utility from the consumption of tradable goods and are risk neutral with a common discount factor $\beta$.

Entrepreneurs run firms. They are specialized in one sector, tradable or non-tradable. They belong to families with a measure one continuum of members and are entitled with equal shares of the family's wealth. At the end of each period, members get their share of the family's wealth and leave to an isolated production site. At the beginning of the next period, a fraction $1-\gamma$ of members exits the economy. The remaining comes back to the family where a measure $1-\gamma$ of new members are born. Members only consume when they exit. Since they are isolated on their production site, exiting members have no choice but to consume their profits. If $\mathcal{W}_{t}^{s}$ denotes the beginning-of-period wealth of a family in sector $s$, consumption is then equal to $(1-\gamma) \mathcal{W}_{t}^{s}$ and internal funds $m_{t}^{s}$ available to start production in period $t$ are equal to $\gamma \mathcal{W}_{t}^{s}$ plus some possible subsidy from the Government, to be detailed later. Production decisions are taken by a representative entrepreneur who maximizes utility, defined as the discounted sum of expected future consumptions of the family $U_{t}=\mathrm{E}_{t} \sum_{s \geq 0} \beta^{s+1} C_{t+s+1}$.

Foreign lenders receive a large enough endowment of tradable goods in each period to provide an infinitely elastic supply of funds at the rate of return $1 / \beta$.

Intermediate firms maximize profits $p_{t}^{Z} y_{t}^{Z}-p_{t} x_{t}^{N}-x_{t}^{T}$.

3.1.3. Financial contracts. Entrepreneurs finance the purchase of inputs out of their internal funds and by issuing one-period bonds. I assume that bonds can only be denominated in tradable goods. Bonds issued in period $t$ by sector $s$ promise a rate of return $r_{t}^{s}$. When the proceeds from the sales of a firm fall short of the promised repayment to bondholders, debt cannot be fully paid back and the entrepreneur is forced to default.

Entrepreneurs are subject to a borrowing constraint. An entrepreneur with internal funds $m_{t}^{s}$ can borrow at most

$$
p_{t}^{Z} z_{t+1}^{s}-m_{t}^{s} \leq(\lambda-1) m_{t}^{s} \quad s=N, T,
$$

where $\lambda \geq 1$ is the financial multiplier of internal funds.

To model the degree of financial openness, I assume that there is an iceberg cost $\tau_{t}^{*}>1$ to international financial transactions. When a foreign lender lends $\tau_{t}^{*}$ units of tradable good to a domestic agent, the domestic agent only gets 1 unit.

Similarly, domestic agents face an iceberg $\operatorname{cost} \tau$ when making loans. I assume that $\tau>\tau_{t}^{*}$ and that $\tau / \tau_{t}^{*}$ is large enough, due to inefficient domestic financial intermediation, so that it is never optimal for an entrepreneur to hold bonds.

3.1.4. Crises. A balance-of-payments crisis in this model is defined as the occurrence of widespread defaults in the non-tradable sector. This happens when $p_{t}\left(z_{t}^{N}\right)^{\theta}<r_{t-1}^{N}\left(p_{t-1}^{Z} z_{t}^{N}-\right.$

$m_{t-1}^{N}$ ), that is for a depreciated enough real exchange rate. Defaults are possible in the non-tradable sector because of the currency mismatch generated by the fact that debt is denominated in tradable goods. This makes balance-sheets of non-tradable firms fragile to unexpected decreases in the relative price. In contrast, firms in the tradable sector are not affected by unexpected price changes and never default. 
During crisis times, the Government intervenes to bail out firms producing non-tradable goods, thus preventing the non-tradable sector from completely disappearing (with zero internal funds and a binding borrowing constraint, defaulting entrepreneurs would not be able to start production at all). Entrepreneurs in sector $\mathrm{N}$ receive a subsidy $S_{t}^{N}>0$, financed by a lump-sum tax on entrepreneurs in sector $\mathrm{T}$. The subsidy is supposed to be small enough to make the borrowing constraint bind in sector $\mathrm{N}$.

3.1.5. Market-clearing conditions. The total supply of intermediate goods is equal to the demand for inputs by both sector $\mathrm{N}$ and sector $\mathrm{T}$ :

$$
y_{t}^{Z}=z_{t+1}^{N}+z_{t+1}^{T} .
$$

Non-tradable goods are only used as an input in the production of intermediate goods:

$$
\left(z_{t}^{N}\right)^{\theta}=x_{t}^{N}
$$

3.1.6. Discussion of the set-up. The model makes two important technological assumptions. First, production takes time. Second, production has decreasing returns to scale with respect to the intermediate input $Z$. This second assumption requires that entrepreneurs are specialized in their sector. Allowing them to choose their sector would amount to assuming constant returns to scale with respect to both the intermediate input and "entrepreneurial skill". These two assumptions are the only ingredients needed for the sectoral dynamics of the model.

The model also assumes two financial frictions: the absence of bonds denominated in nontradable goods and borrowing constraints. These frictions will not play any role in the sectoral dynamics but are crucial to get crises. They are common in models of emerging market crises. The fact that the domestic agents of a developing country are unable to issue debt denominated in foreign currency on international financial markets has been dubbed the Original Sin (Eichengreen and Hausmann, 1999). A similar situation arises in a currency union, since the nominal exchange rate is fixed and nominal debt in the common currency is not contingent to the national price level. Borrowing constraints that introduce a limit on leverage have become common in the macroeconomic literature (Mendoza, 2002; Antras and Caballero, 2009) and several microfoundations have been developed that could be easily embedded in the current paper (Aghion et al., 1999; Schneider and Tornell, 2004; Antras and Caballero, 2009).

The assumption that entrepreneurs enter and exit the economy is usual in models with borrowing constraints (as in Bernanke et al., 1999). In my case, this demographic structure makes it possible to consider steady states corresponding to different degrees of financial openness, as internal funds converge to a finite value whatever the level of the real interest rate. ${ }^{7}$

Finally, the model considers a real economy without nominal frictions. The analysis then abstracts from the exchange rate regime. This assumption is supported by the evidence of Section 2 that the sectoral reallocation takes place in floating as well as in pegged countries (Figure 2e and $\mathrm{f}$ ) and that the exchange rate regime does not predict twin crises (Table 1, column (3)). The case of a fixed exchange rate regime with nominal rigidities will be discussed later.

7. The assumption that entrepreneurs only consume when they exit is a minor restriction. It can be shown that, in any steady state, entrepreneurs would endogenously choose not to consume when they do not exit. 


\subsection{Equilibrium}

3.2.1. Solution concept. In general, the model can have multiple market-clearing prices inside a single time period, corresponding to normal times and crisis times. It is then possible to construct sunspot-driven equilibrium paths with self-fulfilling crises, where the equilibrium outcome in each period depends on the realization of an exogenous sunspot variable.

For the sake of simplicity, my strategy is to focus on perfect foresight equilibria with no uncertainty and zero-probability crises only. In addition, I will look at equilibrium paths where borrowing constraints do not bind. This reduces the model to a simple two-sector small open economy with no financial frictions and makes it easy to study the dynamics. Then, I will ask whether there exists a second market-clearing price, corresponding to a crisis, in a given time period along that perfect-foresight no-crisis dynamics.

3.2.2. Optimization problems. Inow describe in more details the optimization problems of the different agents.

Because of their large endowments, foreign lenders set the rate of return in the model. Given the iceberg $\operatorname{cost} \tau_{t}^{*}$, the riskless borrowing rate in the domestic economy is

$$
r_{t}=\tau_{t}^{*} / \beta
$$

With no uncertainty and no crisis, the rates of return on bonds are simply given by $r_{t}^{N}=r_{t}^{T}=r_{t}$.

The representative entrepreneur of sector $\mathrm{N}$ makes production decisions to maximize the discounted sum of expected future consumptions of the family, given the borrowing constraint (3.1). The value function of this optimization program is: ${ }^{8}$

$$
\begin{aligned}
V_{t}^{N}\left(m_{t}^{N}\right)= & \max _{z_{t+1}^{N}} \beta \mathrm{E}_{t}\left[(1-\gamma) \mathcal{W}_{t+1}^{N}+V_{t+1}^{N}\left(\gamma \mathcal{W}_{t+1}^{N}\right)\right] \\
\text { with } & \mathcal{W}_{t+1}^{N}=p_{t+1}\left(z_{t+1}^{N}\right)^{\theta}-r_{t}\left(p_{t}^{Z} z_{t+1}^{N}-m_{t}^{N}\right), \\
\text { and s. t. } & p_{t}^{Z} z_{t+1}^{N} \leq \lambda m_{t}^{N},
\end{aligned}
$$

for internal funds $m_{t}^{N}$ and beginning-of-period wealth at $t+1 \mathcal{W}_{t+1}^{N}$. The expected value has two terms: the consumption of the $1-\gamma$ exiting family members next period and the continuation value of the measure one family. A similar value function can be written for the representative entrepreneur of sector T with $\mathcal{W}_{t+1}^{T}=\left(z_{t+1}^{T}\right)^{\theta}-r_{t}\left(p_{t}^{Z} z_{t+1}^{T}-m_{t}^{T}\right)$. When borrowing constraints are non-binding, the optimal decision does not depend on internal funds and reduces to a simple first-order condition for each sector:

$$
r_{t}=\frac{\theta \mathrm{E}_{t}\left[p_{t+1}\right]\left(z_{t+1}^{N}\right)^{\theta-1}}{p_{t}^{Z}}=\frac{\theta\left(z_{t+1}^{T}\right)^{\theta-1}}{p_{t}^{Z}} .
$$

The marginal rate of return on intermediate inputs in each sector equals the gross rate of return on bonds.

8. For expositional convenience, I assume that entrepreneurs do not buy bonds. As noted earlier, this is optimal for a high enough iceberg cost on domestic finance, $\tau$. 
Profit maximization with respect to non-tradable inputs by intermediate firms yields

$$
p_{t} x_{t}^{N}=\mu p_{t}^{Z} y_{t}^{Z}
$$

and the first-order condition with respect to tradable inputs, together with the zero profit condition, implies

$$
p_{t}^{Z}=\left(p_{t}\right)^{\mu}
$$

Internal funds are simply given by:

$$
\begin{aligned}
& m_{t}^{N}=\gamma\left[p_{t}\left(z_{t}^{N}\right)^{\theta}-r_{t-1}\left(p_{t-1}^{\mu} z_{t}^{N}-m_{t-1}^{N}\right)\right], \\
& m_{t}^{T}=\gamma\left[\left(z_{t}^{T}\right)^{\theta}-r_{t-1}\left(p_{t-1}^{\mu} z_{t}^{T}-m_{t-1}^{T}\right)\right] .
\end{aligned}
$$

3.2.3. Sectoral dynamics. The dynamics of the no-crisis equilibrium path with nonbinding borrowing constraints reduces to:

$$
\begin{aligned}
& z_{t+1}^{N}=\left[\frac{\theta}{p_{t}^{\mu} r_{t}} \mathrm{E}_{t}\left[p_{t+1}\right]\right]^{\frac{1}{1-\theta}}, \\
& z_{t+1}^{T}=\left[\frac{\theta}{p_{t}^{\mu} r_{t}}\right]^{\frac{1}{1-\theta}}, \\
& p_{t}\left(z_{t}^{N}\right)^{\theta}=\mu p_{t}^{\mu}\left(z_{t+1}^{N}+z_{t+1}^{T}\right) .
\end{aligned}
$$

The scales of production in both sectors, $z_{t}^{N}$ and $z_{t}^{T}$, are predetermined, while the real exchange rate $p_{t}$ is determined in period $t$. Equations (3.10a) and (3.10b) directly derive from the firstorder conditions (3.5) together with (3.7). Equation (3.10c) comes from the market-clearing conditions (3.2) and (3.3), together with (3.7) and the first-order condition of intermediate firms (3.6). Internal funds are then given by (3.8) and (3.9). I only need to keep track of them to make sure that borrowing constraints are not binding.

Definition 1 (No-crisis equilibrium path) Given initial conditions $z_{0}^{N}, z_{0}^{T}, m_{0}^{T}$, an initial debt repayment $b_{0}^{N}$ in sector $N$, and a deterministic exogenous path for the riskless gross interest rate $\left\{r_{t}\right\}_{t \geq 0}$, a no-crisis equilibrium path is a sequence $\left\{z_{t}^{N}, z_{t}^{T}, p_{t}, m_{t}^{N}, m_{t}^{T}\right\}_{t \geq 0}$ that satisfies (3.10a), (3.10b), (3.10c), (3.8), and (3.9), such that the borrowing constraints (3.1) do not bind, and $m_{0}^{N}=\gamma\left[p_{0}\left(z_{0}^{N}\right)^{\theta}-b_{0}^{N}\right]$.

The following proposition establishes the conditions under which there exists a no-crisis equilibrium steady state with strictly positive debt (the proofs of all propositions are in the Supplementary Appendix).

Proposition 1. Suppose $\theta>\gamma$. For $\lambda \geq 1$ and $r>1$ such that $\max \left(\frac{\theta}{\gamma} \frac{1}{\theta+\lambda(1-\theta)}, 1\right)<r<\frac{\theta}{\gamma}$, there is a unique no-crisis equilibrium steady state where entrepreneurs have a strictly positive debt and borrowing constraints do not bind. In this steady state, the debt repayment-to-internal funds ratio, an indicator of leverage, decreases with the gross interest rate $r$. The relative size of both sectors is given by $z^{N} / z^{T}=m^{N} / m^{T}$ and is decreasing in $r$.

The proof consists in first constructing the no-crisis steady state (under the assumption that borrowing constraints do not bind) and then deriving parameter restrictions under which it exists 
(this includes the fact that borrowing constraints should be non-binding) and debt is strictly positive. One of the conditions of existence is that borrowing constraints (3.1) are slack, i.e. $p^{\mu} z^{s}<$ $\lambda m^{s}$ for $s=N, T$. With $m^{s}=\left(\frac{1}{\theta}-1\right) \frac{\gamma r}{1-\gamma r} p^{\mu} z^{s}$ in the steady state, this requires $r>\frac{\theta}{\gamma} \frac{1}{\theta+\lambda(1-\theta)}$. Debt is strictly positive for $r<\theta / \gamma$. For debt to be positive at positive interest rates (i.e. with $r>1$ ) one has to assume that $\theta>\gamma$.

I now turn to the transitory dynamics that follows a permanent increase in financial openness, that is, a permanent decrease in the iceberg $\operatorname{cost} \tau^{*}$ and the domestic riskless rate $r$.

Proposition 2. Consider an economy in a no-crisis equilibrium steady state corresponding to $r_{0}=\bar{r}$ at $t=0$, hit by an unexpected and permanent negative shock $r_{\infty}<r_{0}$ at $t=1$. Suppose $\lambda$ is large enough so that borrowing constraints always remain slack. Then,

- the real exchange rate $p$ overshoots: it appreciates on impact at $t=1$ and depreciates thereafter (for $t \geq 2$ ),

- the scale of production in sector $N, z^{N}$, increases starting at $t=2$,

- the relative size of sector $N$, measured by $z^{N} / z^{T}$, overshoots: it increases at $t=2$ and decreases thereafter (for $t \geq 3$ ),

- if $\gamma \bar{r}$ is not too close to either 0 or 1 , the ratio of sectoral internal funds, $m^{N} / m^{T}$, overshoots with a hump-shaped response starting at $t=1$.

To prove the proposition, the dynamics described in equations (3.10) is reduced to a twodimensional system $\left(z_{t}^{N}, p_{t}\right)$, where $z_{t}^{N}$ is a predetermined state variable (similar to a capital stock), while $p_{t}$ is a non-predetermined jump variable that contemporaneously reacts to unexpected shocks. This system is log-linearized and shown to have saddle-path dynamics, as illustrated by the phase diagram of Figure 3a. The permanent decrease from $r_{0}$ to $r_{\infty}$ moves the saddle-path to the north-east in the $\left(z_{t}^{N}, p_{t}\right)$ plane, leading to an overshooting real exchange rate as shown in Figure $3 b$.

Figure 4 illustrates the transitory dynamics after an increase in financial openness. ${ }^{9}$ Intuitively, as domestic entrepreneurs have suddenly access to cheaper foreign loans to finance their purchases of inputs at $t=1$, they are induced to increase their scale of production. With a predetermined supply, the higher induced demand for non-tradable goods bids up the relative price $p$ in the period of the shock. ${ }^{10}$ In the long run, however, the scale of production in sector $\mathrm{N}, z^{N}$, adjusts to accommodate this larger demand and the real exchange rate subsequently depreciates. Therefore, the real exchange rate overshoots when the shock hits. An important result of the model is that this overshooting lasts for an extended period of time after the shock hits. Indeed, increasing next period's supply of non-tradable goods pushes down their relative price in the next period: from equation (3.10a), this implies a lower optimal scale of production, slowing down the increase. With a slow increase in $z_{t}^{N}$, the decrease in $p_{t}$ from $t=2$ on has to be gradual.

As for the evolution of the sectoral structure, the appreciated real exchange rate hurts the tradable sector by raising the price of the input (in terms of tradable goods), whereas in the nontradable sector this higher cost of inputs is offset by a high expected future price of outputs. So, the relative size of both sectors, measured by their input purchases or by their internal funds, first evolves in a direction favourable to the non-tradable sector until the tradable sector catches up.

9. The calibration is described in Section 4.1. The simulation is performed using Dynare. See Juillard (1996) for details on the relaxation algorithm used.

10. In Equation (3.10c), $p_{t}$ increases with $z_{t+1}^{N}+z_{t+1}^{T}$. 
(a)

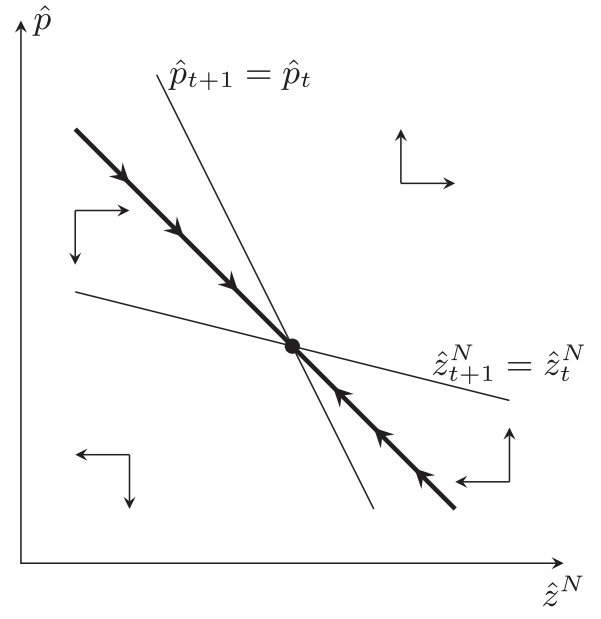

(b) $\uparrow \hat{p}$

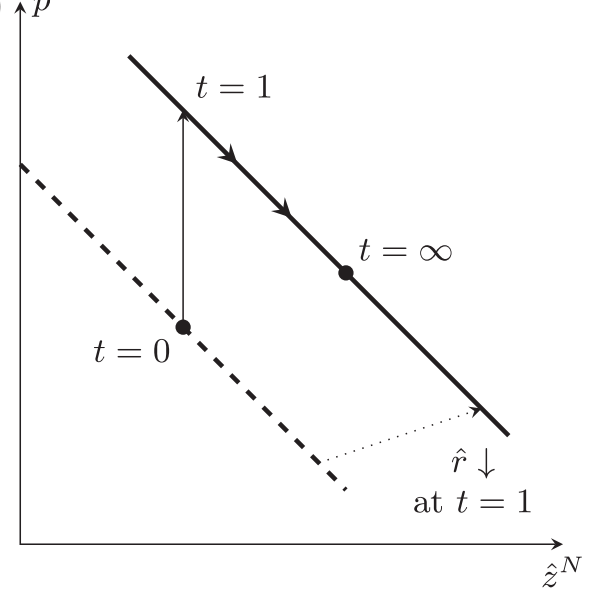

FIGURE 3

Log-linearized dynamics ( $\hat{x}_{t}$ denotes the log-difference between $x_{t}$ and its value in a given steady state). (a) Phase diagram. (b) Dynamics following an unexpected and permanent increase in financial openness

The important feature to get these results is the imperfect mobility of factors. The real exchange rate overshoots when the shock hits because production takes time and cannot adjust instantaneously. The overshooting lasts for many periods because entrepreneurs are specialized in their sector. If they could, they would switch from the tradable to the non-tradable sector until the expected relative price $\mathrm{E}_{1}\left[p_{2}\right]$ was back to its steady state level. The real exchange rate and the relative size $z^{N} / z^{T}$ would overshoot for a single time period. See the Supplementary Appendix for a formal proof.

\subsection{Financial fragility and crises}

I now look for a second market-clearing price corresponding to a crisis, along the no-crisis equilibrium path. In this equilibrium, the price of non-tradables is too low to cover the debt repayment (denominated in tradables) promised by firms producing non-tradables. Entrepreneurs of sector $\mathrm{N}$ default, their beginning-of-period wealth is zero, and exiting members of the family do not consume.

Proposition 3. Consider an economy following a no-crisis equilibrium path. If

$$
\frac{r_{t-1}\left(p_{t-1}^{\mu} z_{t}^{N}-m_{t-1}^{N}\right)}{\gamma\left[\left(z_{t}^{T}\right)^{\theta}-r_{t-1}\left(p_{t-1}^{\mu} z_{t}^{T}-m_{t-1}^{T}\right)\right]}>\mu \lambda,
$$

then there exists a second market-clearing price $p_{t}^{\text {crisis }}<p_{t}$ at which non-tradable firms default. A necessary condition for the existence of two market-clearing prices is

$$
\mu \gamma \lambda>1
$$

An equilibrium path is said to be financially fragile in period $t$ when condition (3.11) is satisfied. Then, a crisis can be triggered by a non-anticipated expectational shock that makes agents coordinate on the lower market-clearing price. Of course, by definition of the no-crisis equilibrium 
(a) $p$

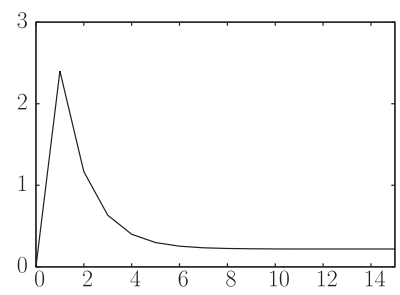

(d) $\mathrm{mN} / \mathrm{mT}$

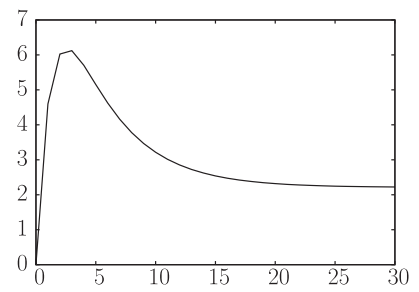

(b) $z N, z T$

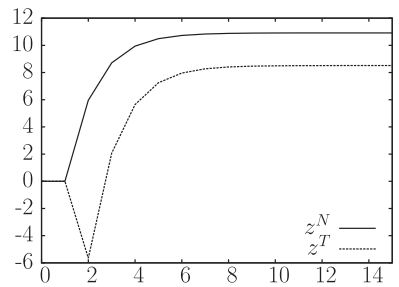

(e) Current account

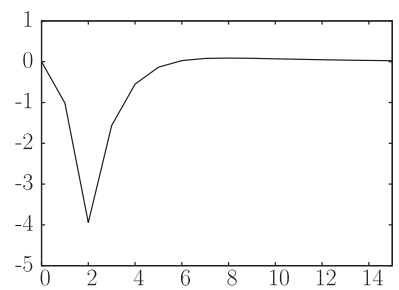

(c) $z N / z T$

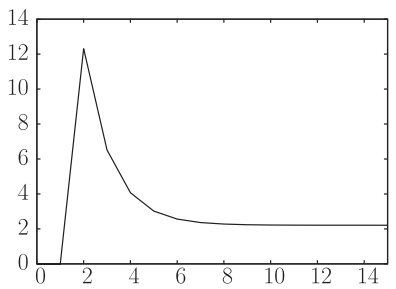

(f) Financial fragility

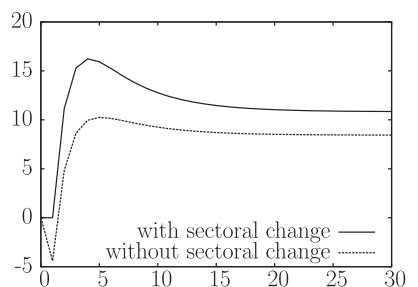

FIGURE 4

No-crisis equilibrium. Financial openness permanently increases at $t=1$ by 1 percentage point. Variables are expressed as a percentage deviation from the initial steady state. The current account is normalized by the value of production and expressed as an absolute deviation from the initial steady state, in percentage points. (f) Contribution of sectoral change

to financial fragility; solid line: $r_{t-1}\left(p_{t-1}^{\mu} z_{t}^{N}-m_{t-1}^{N}\right) / m_{t}^{T}$; dashed line: $r_{t-1}\left(p_{t-1}^{\mu} z_{t}^{N}-m_{t-1}^{N}\right) / m_{t}^{N} \times\left(m^{N} / m^{T}\right)_{\text {constant }}$ where $m^{N} / m^{T}$ is kept constant at its initial value

path, crises are zero-probability events and they remain in the background of the dynamics. Along a no-crisis equilibrium path, condition (3.11) can be rewritten

$$
\frac{r_{t-1}\left(p_{t-1}^{\mu} z_{t}^{N}-m_{t-1}^{N}\right)}{m_{t}^{T}}=\underbrace{\frac{m_{t-1}\left(p_{t-1}^{\mu} z_{t}^{N}-m_{t-1}^{N}\right)}{\begin{array}{c}
\text { sectoral } \\
\text { structure }
\end{array}}}_{\begin{array}{c}
\text { financial } \\
\text { structure of N }
\end{array}} \times \underbrace{\frac{m_{t}^{N}}{m_{t}}}_{\frac{m_{t}^{T}}{m_{t}^{N}}}>\lambda .
$$

A no-crisis equilibrium path is financially fragile when the product of two factors is large enough. The first factor relates debt service to internal funds and reflects the financial structure of balance sheets in sector N. As debt is denominated in tradable goods, it also measures the extent of the currency mismatch. The second factor describes the relative size of both sectors, measured by their internal funds, and is an indicator of the sectoral structure of the whole economy. ${ }^{11}$

The steady state value of both factors decreases in $r$ (see Proposition 1). In the long run, more financially opened economies are more leveraged and have a larger non-tradable sector. ${ }^{12}$ The following proposition shows under what condition this is enough to make the steady state financially fragile.

11. In condition (3.11'), $m^{N}$ and $m^{T}$ correspond to normal-time internal funds.

12. The monotonicity of $m^{N} / m^{T}$ in $r$ depends on the simplifying assumption that the non-tradable good is only used as an input. It does not generalize to the case when it also enters the consumption basket. In such a case, however, $r\left(p^{Z} z^{N}-m^{N}\right) / m^{T}$ would still be strictly decreasing in $r$. 
Proposition 4. Suppose $\mu \gamma \lambda>1$. There is a unique $r_{\text {frag }}$ in $\left(\max \left(\frac{\theta}{\gamma} \frac{1}{\theta+\lambda(1-\theta)}, \theta \mu\right), \frac{\theta}{\gamma}\right)$ such that $\frac{r\left(p^{\mu} z^{N}-m^{N}\right)}{m^{T}}>\mu \lambda$ if and only if $r<r_{\text {frag. }}$. If $r_{\text {frag }}>1$, a no-crisis equilibrium steady state is financially fragile for all $r$ in $\left(1, r_{\max }\right)$. A sufficient condition for $r_{\text {frag }}>1$ is $\theta>\frac{\lambda}{(\lambda-1+1 / \gamma)}$.

After a permanent decrease in the transaction $\operatorname{cost} \tau^{*}$, leverage in sector $\mathrm{N}$, as measured by the ratio of debt repayment to internal funds, increases to its higher new steady state value. ${ }^{13}$ Proposition 2 showed that the ratio of internal funds $m_{t}^{N} / m_{t}^{T}$ displays a hump-shaped dynamics for a wide range of parameters. As a result, the financial fragility ratio $r_{t-1}\left(p_{t-1}^{\mu} z_{t}^{N}-m_{t-1}^{N}\right) / m_{t}^{T}$ can overshoot in the medium run, as shown in Figure $4 \mathrm{f}$ (solid line). This makes it more likely for the economy to become financially fragile during the transition to a more open capital account.

As the financial structure of sector $\mathrm{N}$ and the sectoral structure enter multiplicatively in the financial fragility ratio, the two factors reinforce each other. By how much does each factor contribute to financial fragility? Figure $4 \mathrm{f}$ shows the evolution of $r_{t-1}\left(p_{t-1}^{\mu} z_{t}^{N}-m_{t-1}^{N}\right) / m_{t}^{T}$ with (solid line) and without (dashed line) changes in $m^{N} / m^{T}$. In the long run, the larger value of the ratio mainly comes from a higher leverage but the overshooting of relative internal funds does significantly affect the transitory dynamics.

\subsection{Discussion of the results}

3.4.1. Sectoral dynamics. Sectoral dynamics are entirely driven by the technological assumptions. In particular, the demand side of the model plays no role in these dynamics. By definition of the no-crisis equilibrium path, financial frictions play no role either in the transitory dynamics. This suggests that booms in the non-tradable sectors should be observed during episodes of large capital inflows regardless of the degree of financial development, that is, both in emerging and advanced economies. This is consistent with the empirical evidence presented in Section 2.

3.4.2. The role of financial frictions. Financial frictions are however important for financial fragility. This is consistent with the logit estimations of Section 2, which show that emerging countries, who arguably face stronger borrowing constraints, have a higher probability of crises. As in Krugman (1999), Aghion et al. (2004), and Schneider and Tornell (2004), the crisis mechanism relies on the interplay between currency mismatches and borrowing constraints. Borrowing constraints are in particular necessary to limit the demand for non-tradable goods during crises, not only in sector $\mathrm{N}$ but also in sector $\mathrm{T}$ : a larger financial multiplier in sector $\mathrm{T}$ would weaken the case for financial fragility.

However, the financial multiplier cannot be too small: borrowing constraints have to remain slack, at least in sector $\mathrm{N}$, so that a normal-time equilibrium exists, a result similar to Aghion et al . (2004) and Schneider and Tornell (2004). More precisely, the financial multiplier $\lambda$ that enters condition (3.12) is that of sector $\mathrm{N}$. As regards sector T, the definition of a no-crisis equilibrium path can be easily extended to allow for a binding constraint: this would simply slow down growth in the tradable sector during its catching-up phase.

3.4.3. The role of the sectoral structure in financial fragility. Condition (3.11') shows that a sectoral structure largely oriented towards the production of non-tradable goods favours

13. The leverage ratio in sector $\mathrm{N}$ actually decreases when the shock hits since debt service is predetermined while internal funds increase with the real appreciation. It only starts increasing in the following period. Convergence can be monotonic or slightly hump-shaped, depending on parameter values. 
the possibility of crises. Intuitively, when borrowing is constrained, the sectoral structure is what determines the level of the real exchange rate needed to adjust the lower demand for nontradable goods. Then, for a large enough (foreign currency) debt in sector $\mathrm{N}$ - the first factor in condition (3.11') — this depreciated level of the real exchange rate leads to defaults and a crisis.

3.4.4. Anticipated crises. To model anticipated crises, a predictable selection rule should be introduced to coordinate agents across the two possible outcomes when both exist at the same time. Suppose, as Cole and Kehoe (2000), that there is an exogenous sunspot variable independently and uniformly distributed on the interval $[0,1]$ and denote $\pi$ the probability of a crisis in a period where a crisis is possible. A possible selection rule could be to coordinate on the crisis-time real exchange rate when (a) it exists, (b) it was predicted to exist with probability $\pi$ in the previous period, and (c) the sunspot variable is lower than $\pi$. The probability of crisis would then be endogenous: equal to 0 or $\pi$ depending on whether the economy is financially fragile or not. When this probability is non-zero, entrepreneurs of sector $\mathrm{N}$ would have to pay a higher rate of return $r_{t}^{N}>r_{t}$ for foreign lenders to break even: $r_{t}=(1-\pi) r_{t}^{N}+\pi \frac{p_{t+1}^{\text {crisis }}\left(z_{t+1}^{N}\right)^{\theta}}{p_{t}^{\mu} z_{t+1}^{N}-m_{t}^{N}}$. The no-crisis equilibrium path studied in this article corresponds to the limit $\pi \rightarrow 0$. By continuity, results concerning financial fragility when $\pi=0$ should also be valid when $\pi>0$ provided that the probability of crisis $\pi$ is low enough.

3.4.5. Crises triggered by shocks on fundamentals. So far, crises were supposed to be triggered by self-fulfilling purely expectational shocks. An alternative is to consider unexpected negative shocks on $\lambda$. If $\lambda<1 /(\mu \gamma)$ when (3.11') holds, the normal-time withinperiod equilibrium disappears and the economy jumps to the remaining crisis-time within-period equilibrium.

3.4.6. Crises in economies with a fixed exchange rate regime. As explained earlier, the exchange rate regime does not seem to matter for the sectoral reallocation or the occurence of twin crises. However, it plays an important role during crises. Empirically, large real depreciations have taken the form of nominal depreciations. In contrast, crisis countries in the periphery of the euro area, where such an adjustment is impossible, have experienced limited real depreciation so far. Some form on nominal rigidity is needed to account for this different behaviour. Denote $p^{T}\left(p^{N}\right)$ the nominal price in the tradable (non-tradable) sector. By the law of one price, we have $p^{T}=e$ where $e$ is the nominal exchange rate. ${ }^{14}$ The relative price of non-tradables is then $p=p^{N} / e$. Equilibria described in the model obtain if either the nominal exchange rate or the price of non-tradables is fully flexible. This is not the case in an economy with nominal rigidities and a fixed exchange rate regime. The Supplementary Appendix presents such a framework with monopolist competition and pre-set prices in the non-tradable sector. Production in that sector is now given by $u_{t}\left(z_{t}^{N}\right)^{\theta}$, where $u_{t}$ is the rate of capacity utilization. Entrepreneurs decide at the end of period $t-1$ how much to produce in period $t$. At the beginning of period $t$, after shocks on exogenous variables are known but before they know whether a self-fulfilling crisis occurs, they set prices. When they know whether a crisis occurs or not, they set capacity utilization. Under these assumptions, the dynamics of the no-crisis equilibrium path is unchanged. During a crisis, the relative price of non-tradables, $p_{t}$, takes its pre-set normal-time value and adjustment comes from capacity utilization $u_{t}$ instead. Entrepreneurs in sector $\mathrm{N}$ default, not because they sell their 
goods at a lower price, but because they sell less of them. The sufficient condition of financial fragility (3.11') still holds.

\section{QUANTITATIVE ANALYSIS}

\subsection{The model}

To explore the quantitative features of the model, the mechanism has to be embedded into a richer set-up. In the simple framework studied so far, the focus was exclusively on riskneutral entrepreneurs, intermediate goods were the only factor of production, and the final good consumed by agents was only made of tradable goods. In this section, three additional elements are introduced: (i) there is a standard representative household with concave utility, (ii) the final good is made of both tradable and non-tradable goods, and (iii) production now requires the use of labour and capital, providing new adjustment margins. This more realistic framework will be used to shed light on several episodes of large capital inflows identified in Section 2. The exposition of the full model can be found in the Supplementary Appendix. Here, I only briefly describe the new ingredients introduced.

4.1.1. A more realistic set-up. To embed the simple framework of Section 3 into a conventional macroeconomic model, I consider a representative household modelled as in Gertler and Karadi (2011), where members are either workers, entrepreneurs in sectors N and T, and financial intermediaries. Entrepreneurs are modelled as in the simple set-up of Section 3. Exiting entrepreneurs return to the household bringing their share of wealth as dividends. Financial intermediaries are similar to entrepreneurs but accumulate capital $K$ instead of engaging in production. They are endowed with $L^{F}=1$ unit of specialized labour and subject to a borrowing constraint similar to the one for entrepreneurs. The representative household has Greenwood-Hercowitz-Huffman (GHH) preferences given by utility $U_{t}=\mathrm{E}_{t} \sum_{s>0} \beta^{s} u\left(c_{t+s}-\right.$ $h\left(L_{t+s}\right)$ ), where $c$ is the consumption of final goods and $L$ the labour supplied by workers. ${ }^{15}$ The household is also subject to a borrowing constraint: it cannot directly issue debt.

Entrepreneurs use an input $\mathrm{Z}$ to produce tradable and non-tradable goods as in the simple model. The production of tradable goods is now $e^{a_{t-1}^{T}}\left(z_{t}^{T}\right)^{\theta}$, where $a^{T}$ is an efficiency wedge between the tradable and the non-tradable sectors, which I will refer to as sector-T productivity. The two goods are used to produce a final good of price $p_{t}^{F}$ with a Cobb-Douglas production function: $y_{t}^{F}=\left(\frac{x_{t}^{T}}{1-\mu}\right)^{1-\mu}\left(\frac{x_{t}^{N}}{\mu}\right)^{\mu}$, where $x_{t}^{T}\left(x_{t}^{N}\right)$ is the input of tradables (non-tradables) used in the production of the final good $F$. The input $\mathrm{Z}$ is produced by a competitive sector using intermediate goods $J$, capital $K$, labour from workers $L$, and labour from financial intermediaries $L^{F}$ :

$$
y_{t}^{Z}=e^{a_{t}^{Z}} J_{t}^{\eta}\left[K_{t}^{\alpha}\left(L_{t}^{F}\right)^{\epsilon} L_{t}^{1-\alpha-\epsilon}\right]^{1-\eta},
$$

where $a^{Z}$ measures the efficiency of production and is similar to total factor productivity (TFP) in one-sector models. ${ }^{16}$ Capital depreciates at rate $\delta$ and is subject to an installation cost $\Phi\left(K_{t+1}, K_{t}\right)$ in final goods, where $\Phi$ is homogeneous of degree one.

15. With GHH preferences, labour supply does not react to changes in the level of consumption, making employment very procyclical. This specification is often used in models of small open emerging economies. Neumeyer and Perri (2005) show that GHH preferences are essential to get the negative correlation between GDP and the real interest rate that is present in the data.

16. The simple framework of Section 3 corresponds to the case $\eta=1$. 


\begin{tabular}{ll}
\multicolumn{2}{c}{ TABLE 3 } \\
Calibration \\
\hline Parameter & Value \\
\hline Discount factor & $\beta=0.99$ \\
Relative risk aversion & $\sigma=2$ \\
Frisch elasticity & $\chi=1$ \\
Capital share & $\alpha=0.37$ \\
Depreciation rate of capital & $\delta=0.06$ \\
Installation cost of capital & $\varphi=1$ \\
\hline Initial iceberg cost & $\tau_{0}^{*}=1.033$ \\
Degree of decreasing returns & $\theta=0.90$ \\
Share of intermediate goods & $\eta=0.54$ \\
Share of financial intermediation & $\epsilon=0.05$ \\
Share of non-tradable goods & $\mu=0.65$ \\
\hline
\end{tabular}

Financial fragility in this extended model is defined as the existence of a second marketclearing price with defaults and binding borrowing constraints. As in the simple model, financial fragility takes place when the financial fragility ratio $r_{t-1}\left(p_{t-1}^{Z} z_{t}^{N}-m_{t-1}^{N}\right) / m_{t}^{T}$ exceeds some threshold.

I assume the following stochastic processes for the three exogenous variables:

$$
\begin{aligned}
& \tau_{t}^{*}=\tau_{t-1}^{*}+\epsilon_{t}^{\tau}, \\
& a_{t}^{Z}=\rho^{Z} a_{t-1}^{Z}+\epsilon_{t}^{Z}, \\
& a_{t}^{T}=\rho^{T} a_{t-1}^{T}+\epsilon_{t}^{T} .
\end{aligned}
$$

I follow the theoretical section closely by assuming that the iceberg cost is subject to permanent shocks. The two productivity shocks follow autoregressive processes. The innovations $\epsilon_{t}^{\tau}, \epsilon_{t}^{Z}$, and $\epsilon_{t}^{T}$ are normally distributed with mean 0 and standard deviations $\sigma^{\tau}, \sigma^{Z}$, and $\sigma^{T}$, respectively.

The Supplementary Appendix shows that this extended model behaves similarly to the simple framework of Section 3.

4.1.2. Calibration. The model is calibrated on a typical small open economy subject to large capital inflows leading to a twin crisis. More specifically, I will focus on the countries of Table 2: Finland, Malaysia, Thailand, Argentina, Colombia, Greece, and Spain, which include the four well-known sets of crises: the Nordic crisis, the Asian crisis, crises in Latin America, and crises at the periphery of the euro area. ${ }^{17}$

The time period is set to six months. I choose the following functional forms for the utility function, the disutility of labour and the installation cost of capital: $u(x)=\frac{x^{1-\sigma}}{1-\sigma}, h(L)=\frac{\chi}{1+\chi} L^{\frac{1+\chi}{\chi}}$, and $\Phi\left(K_{t+1}, K_{t}\right)=\frac{1}{2} \varphi K_{t}\left(\frac{K_{t+1}}{K_{t}}-1\right)^{2}$. The calibration of the model's parameters is reported in Table 3. Most of the parameters are standard in the business cycle literature and their calibration is discussed in the Supplementary Appendix. Here, I only focus on parameters specific to this article.

The initial iceberg cost $\tau_{0}^{*}$ corresponds to the spread between the domestic marginal return on capital and the world interest rate before financial integration. In emerging markets, this

17. I exclude Sweden, due to the short duration of the episode (three years). 
spread, as measured by the EMBI, was around 1000 basis points in 1990, prior to capital account liberalization; it increased above 1000 basis points in 1995 and 1998, two periods of financial stress during which many countries lost market access, and to 700 basis points in the recent global liquidity crisis of 2008. In the recent crisis of the euro area, the sovereign bond spread against Germany increased to around 500 basis points in Spain and Italy as capital stopped flowing to these countries. On the light of this evidence, I set $\tau_{0}^{*}$ to match a spread of 700 basis points per year.

The degree of decreasing return to scale $\theta$ is chosen to be consistent with the literature on firm dynamics. Atkeson and Kehoe (2005) argue that a value of 0.95 is appropriate for the degree of decreasing returns at the plant level based on a survey of the large existing empirical literature; taking into account the effect of imperfect competition, they retain a lower effective value of 0.85. I set $\theta$ to the mean of these two values. Cagetti and De Nardi (2009) obtain the same value of 0.9 when they calibrate their model of entrepreneurship to match U.S. data.

The parameter $\eta$ is set to match a share of intermediate goods in total production of $46 \%$, as recommended by Jones (2013). The share of financial services $\epsilon$ is calibrated from input-output data to match a share of inputs from finance and real estate in production equal to $4 \%$ on average for Finland, Argentina, Greece, and Spain. ${ }^{18}$ The share of non-tradable goods $\mu$ in consumption, investment, and intermediate goods can also be measured in input-output tables. It is equal to $61 \%$ on average for those countries. The true share could be even higher: Burstein et al. (2005) argue that some goods traditionally classified as tradables are in fact local goods sheltered from foreign competition. In the case of Argentina, they suggest that local goods could represent up to $22 \%$ of tradable consumption goods. Applying this correction raises the share of non-tradable goods to $69 \%$. However, investment and intermediate goods are likely to have a lower share of local goods than consumption goods. Therefore, I make a conservative choice and set $\mu$ to the average of the two values, $65 \%$.

Finally, $\gamma$ is estimated with Bayesian methods using the model-implied relationship between this parameter and the debt-to-equity ratio in the initial steady state. The prior for the debt-to-equity ratio is chosen to reflect available evidence from firm-level data. See the Supplementary Appendix for details.

\subsection{Sectoral dynamics during historical episodes of large capital inflows}

I now confront this extended model with the data to see if the mechanism of sectoral reallocation highlighted in Section 3 might have played a role during the seven episodes of large capital inflows mentioned above: Finland, Malaysia, Thailand, Argentina, Colombia, Greece, and Spain.

For each episode, I decompose the observed dynamics of the main variables in movements due to several wedges in the spirit of Chari et al. (2007). In addition to the main exogenous variable considered in the article, the iceberg $\operatorname{cost} \tau_{t}^{*}$ which sets the cost of borrowing $r_{t}$, I also consider two wedges introduced in the quantitative model: the multisector efficiency wedge $a^{Z}$, akin to a TFP shock, and the efficiency wedge between the tradable and the non-tradable sectors, $a^{T}$, akin to sector-T productivity. I use three observables: the current account and the N-to-T ratio, which are key to the mechanism studied, and real GDP, which is needed to identify movements in the efficiency wedges. Introducing the efficiency wedge $a^{Z}$ is important since changes in TFP are likely to affect the current account and the N-to-T ratio through their effect on both the supply of output and the demand for inputs. The sectoral wedge $a^{T}$ is important since it can directly account for movements in the $\mathrm{N}$-to-T ratio.

18. I use OECD input-output tables. Tables for the remaining countries are not available. 
I use the same yearly data as in Section 2. For each episode, the data sample starts one year before the beginning of the episode and stops one year after its end. ${ }^{19}$ The decomposition is carried out using a diffuse Kalman filter. I assume that the iceberg $\cos t \tau^{*}$ is initially equal to $\tau_{0}^{*}$ and that shocks $\epsilon_{t}^{\tau}$ only start at the beginning of the episode (i.e. one year after the beginning of the time sample).

Figure 5 displays the resulting shock decomposition of the three observable variables, as well as the estimated decrease in the borrowing rate for all seven countries. In general, TFP and sector-T productivity shocks (medium grey and light grey bars, respectively) are necessary to account for the dynamics of GDP, but most of the dynamics of the current account and the N-to-T ratio is accounted for by negative shocks to the iceberg cost (dark grey bars) which substantially decrease the cost of financing.

Figure 6 looks in more details at the case of Thailand. According to the empirical evidence of Section 2, Thailand experienced an episode of large capital inflows starting in 1990, which ended up in a twin crisis in 1997. The beginning of the episode of capital inflows coincides with the date of (partial) liberalization of financial markets as documented by Kaminsky and Schmukler (2003), that is, January 1990. Figure 6 compares the evolution of the economy when the model is fed with both productivity shocks and when the only shock is the iceberg cost. The productivity shocks account for most of the increase in GDP above its trend, but explain only a small fraction of movements in the current account and the N-to-T ratio. In particular, with productivity shocks only, both variables quickly revert to their steady state after their initial response. The decrease in the iceberg cost, on the contrary, fits well the observed dynamics of these two variables.

The intuition of these results is the following. As in the simple model, a decrease in the iceberg cost leads to both a persistent increase in the N-to-T ratio and a persistent current account deficit, consistent with the behaviour of these two variables during the episodes of large capital inflows.

Consider instead the response to productivity shocks (see the Supplementary Appendix for impulse-response charts). A positive TFP shock also leads to a persistent increase in the N-to-T ratio: as $a_{t}^{Z}$ increases, intermediate inputs $\mathrm{Z}$ become cheaper and it is optimal for entrepreneurs to increase their scale of production as they would do with a lower cost of financing. However, with a higher production, the need to import tradable goods is reduced, yielding only a small and short-lived current account deficit. TFP shocks, then, do not account well for the observed current account dynamics.

A negative sector-T productivity shock would directly result in a higher N-to-T ratio. It would also lead to a current account deficit as the economy would need to import the tradable goods it no longer produces. However, it would imply a decrease in GDP, which is hard to reconcile with the data.

Overall, these results suggest that increased financial integration resulting in a lower cost of external finance is likely to have played an important role in the sectoral reallocation of resources.

\subsection{Financial fragility and crises}

What does this imply for financial fragility and crises? I focus on the case of Thailand to show how the sectoral reallocation triggered by capital inflows might have increased financial fragility.

4.3.1. Financial fragility. As in the simple model, financial fragility occurs when the ratio $r_{t-1}\left(p_{t-1}^{Z} z_{t}^{N}-m_{t-1}^{N}\right) / m_{t}^{T}$ exceeds a threshold that depends on the financial multiplier $\lambda$.

19. In the case of Finland, where the episode is short, I start the sample two years before the beginning of the episode. 
Finland
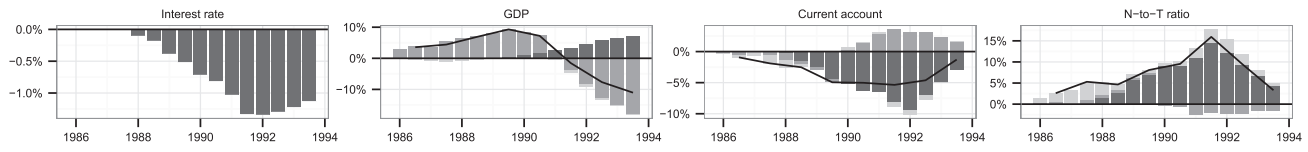

Malaysia
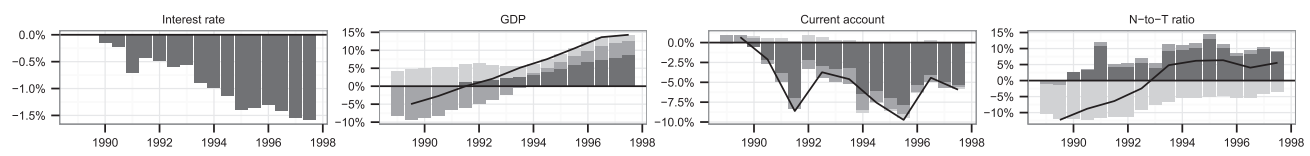

Thailand
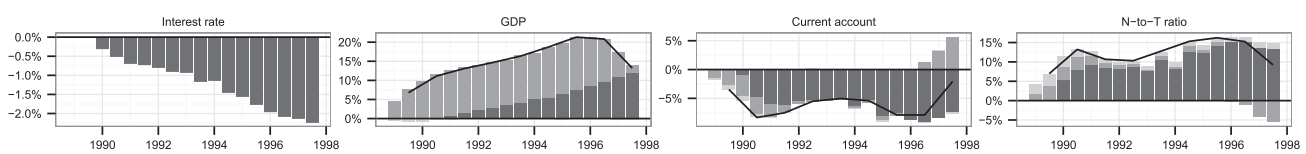

Argentina
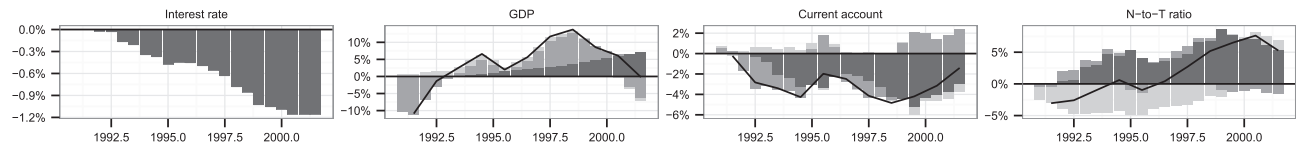

Colombia
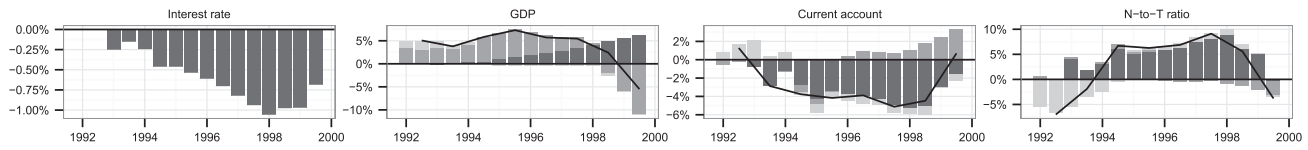

Greece
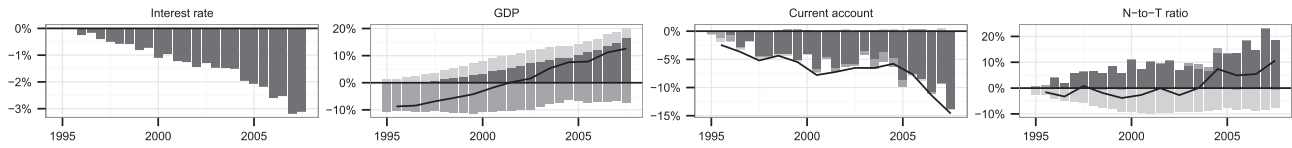

Spain
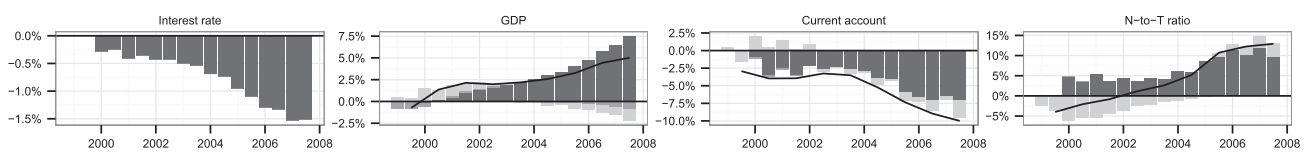

Iceberg cost

Total factor productivity

Sector-T productivity

FIGURE 5

Shock decomposition in episodes of large capital inflows. Black solid line: observed variable. Grey bars: contribution to observed variable from shocks

I assume the economy is initially, in $1988 \mathrm{H} 2$, in a steady state corresponding to the iceberg $\operatorname{cost} \tau_{0}^{*}$. Then, I feed the model with the shocks $\left\{\epsilon_{t}^{\tau}\right\}$ backed out from the data on the time period 1989-1997 as described in the previous exercise. These shocks imply a gradual decrease in the 

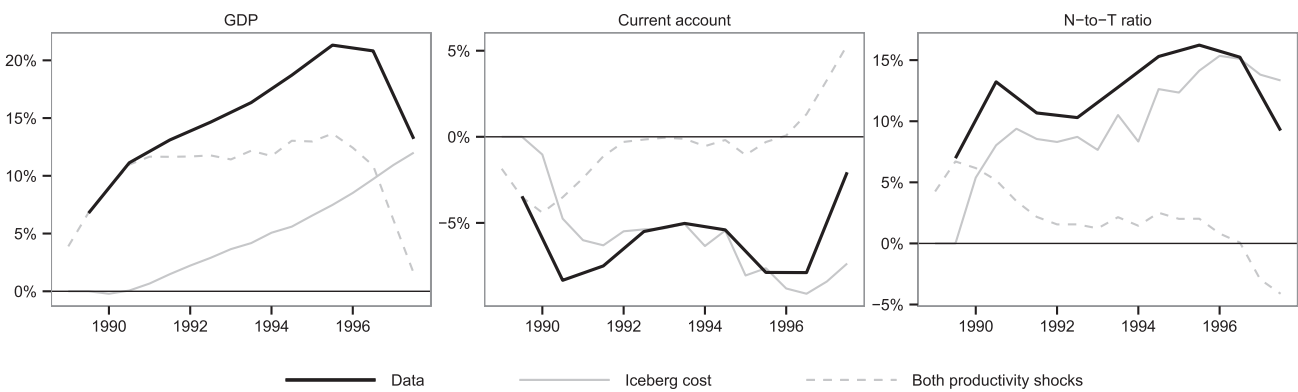

FIGURE 6

Counterfactuals for Thailand: simulations with the shock on the iceberg cost only and with both productivity shocks at the same time

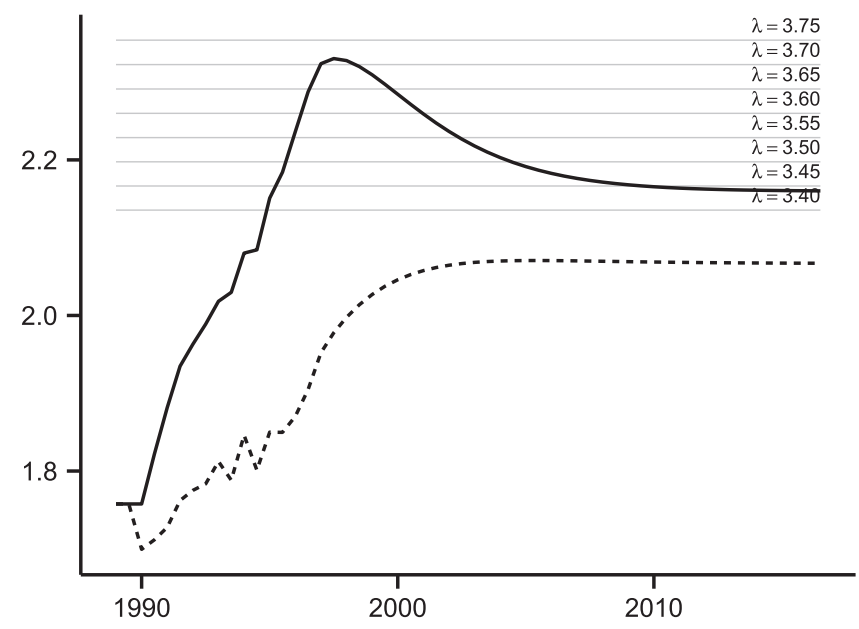

FIGURE 7

Evolution of financial fragility when the economy is hit by estimated shocks to the iceberg cost $\tau^{*}$. Solid black line: financial fragility ratio $r_{t-1}\left(p_{t-1}^{Z} z_{t}^{N}-m_{t-1}^{N}\right) / m_{t}^{T}$. Dashed black line: $r_{t-1}\left(p_{t-1}^{Z} z_{t}^{N}-m_{t-1}^{N}\right) / m_{t}^{N} \times\left(m^{N} / m^{T}\right)$ constant where $m^{N} / m^{T}$ is kept constant at its initial value. Thin grey lines: thresholds corresponding to different values of $\lambda$

iceberg $\operatorname{cost} \tau_{t}^{*}$ and in the rate of return of bonds $r_{t}$. Figure 7 shows the resulting evolution of the financial fragility ratio $r_{t-1}\left(p_{t-1}^{Z} z_{t}^{N}-m_{t-1}^{N}\right) / m_{t}^{T}$ (solid black line). The thin grey lines represent the threshold above which the economy is financially fragile, for different values of the financial multiplier $\lambda$. A stronger borrowing constraint (a lower $\lambda$ ) makes financial fragility more likely.

As the figure shows, the financial fragility ratio displays significant overshooting in the medium term. For a given value of the financial multiplier, the economy is more likely to experience financial crises in the medium term than in the long term. Financial fragility requires at least $\lambda \lesssim 3.71$ during the transition. With $\lambda \lesssim 3.43$, the economy displays financial fragility even in the final steady state. The ratio is particularly large at the time of the actual crisis, 1997.

By how much does the sectoral reallocation contribute to financial fragility? The dashed black line shows the evolution of the same ratio holding $\mathrm{m}^{N} / \mathrm{m}^{T}$ constant at its initial value. While this modified ratio increases significantly over time, reflecting a higher leverage in sector $\mathrm{N}$ as shown by Equation (3.11'), it does not display any overshooting. The sectoral reallocation is key 
TABLE 4

Observed and simulated peak-to-trough evolution of key variables during the crisis in Thailand

\begin{tabular}{lcccccc}
\hline & $p^{F}$ & $I$ & $L$ & GDP & NX & DD \\
\hline Observed data & & & & & & \\
Model & -36 & -60 & -4 & -13 & +17 & -59 \\
$\lambda=3.70$ & -39 & -50 & -4 & -1 & +35 & -65 \\
$\lambda=3.60$ & -40 & -52 & -5 & -2 & +36 & -67 \\
$\lambda=3.50$ & -41 & -54 & -5 & -2 & +37 & -68 \\
$\lambda=3.40$ & -43 & -55 & -6 & -2 & +37 & -70 \\
\hline
\end{tabular}

Notes: I: real investment. NX: net export reversal as a share of initial GDP. DD: domestic demand reversal as a share of initial GDP. All reported figures are \% change, except the net export and domestic demand reversals which are absolute changes in percentage points. In the data, $p^{F}$ refers to the bilateral CPI-based real exchange rate with the U.S. dollar. To construct measures of $N X$ and $D D$ in tradable goods, I multiply current prices in domestic currency by the nominal exchange rate with the U.S. dollar and deflate by the U.S. CPI. Peak-to-trough changes are computed on half-yearly data, except employment which uses yearly data.

to getting stronger financial fragility in the medium term. This confirms the result obtained in the simple model.

4.3.2. Crises. The aim of the model is to reproduce the pre-crisis dynamics more than the crisis itself. However, it is instructive to look at the evolution of the main variables predicted by the model should a crisis take place. Using the same simulation as before, I assume that a crisis takes place in $1997 \mathrm{H} 1$. Table 4 reports the simulated changes in several key variables in the period of the crisis and compares them with the observed peak-to-trough changes in the data. The equilibrium corresponding to a crisis depends on the parameter of the borrowing constraint $\lambda$. I report results for $\lambda \in[3.40,3.70]$, that is, for $\lambda$ low enough to get financial fragility in $1997 \mathrm{H} 1$ (Figure 7). At the lower value of $\lambda=3.40$, the economy stays financially fragile in the new steady state.

Overall, the simulated magnitudes are close to the data, which is remarkable given the simplicity of this multiple equilibria framework. In particular, the model does a good job at producing the right order of magnitude for the real depreciation, around $40 \%$. With a binding borrowing constraint for financial intermediaries, investment in the model drops sharply during the crisis, by around 50-55\%, compared to $60 \%$ in the data. The magnitude of this simulated decrease in investment depends on the strength of the borrowing constraint $(\lambda)$ and the size of internal funds of intermediaries, driven by the share $\epsilon$ of financial services.

The model predicts a 5\% drop in employment, very close to the decrease observed in the data. The mechanism behind the fall in employment is the following. With binding constraints, the demand for inputs drops during the crisis, inducing a lower wage bill in sector Z. For a given supply of labour, the wage $w$ decreases. The price of the final good, $p^{F}$, also decreases during a crisis, but to a lesser extent since it partly consists of tradable goods. As a result, the real wage $w / p^{F}$ decreases, which induces households to reduce their labour supply. GHH preferences are crucial to get this result (see below).

Given the decrease in employment, the model predicts a $2 \%$ drop in GDP. While this is already substantial for an endogenous decrease driven by a self-fulfilling crisis, it falls short of the $13 \%$ collapse observed in the data. The difference comes from the decrease in measured total factor productivity (TFP) which the model was not designed to produce. A plausible explanation for the decline in measured TFP in the data is the banking crisis that took place in 1997 and that very likely disrupted production processes. The counterpart to the banking crisis in the model is the fact that financial intermediaries massively default on their debt. 
The model assumes that those defaults have no effect on production, arguably an unrealistic assumption. ${ }^{20}$

The model does not do a good job at matching the reversal in net exports. It produces a reversal that amounts to about $35 \%$ of the initial GDP, compared to $17 \%$ in the data. The difference can be explained by the fact that GDP declines less than in the data as discussed above. For a given change in domestic demand, this implies a larger net export reversal. One way to correct for this is to consider the reversal in domestic demand measured in tradable goods instead of the net export reversal. ${ }^{21}$ The model reproduces the former better (see the last column of Table 4).

On the whole, these results show how a model with multiple equilibria can successfully reproduce a crisis of a very large magnitude.

Wealth effect in labour supply As explained above, GHH preferences, which imply no wealth effect in labour supply, are important to get employment dynamics right during a crisis. As is well known, with a wealth effect in labour supply, households would react to the lack of resources during a sudden stop by working more, leading to an economic expansion (Chari et al., 2005). Consider for example the case of separable intratemporal utility: $u(c, L)=\frac{c^{1-\sigma}}{1-\sigma}-\frac{\chi}{1+\chi} L^{\frac{1+\chi}{\chi}}$. Then, the real exchange rate, investment, and the trade balance would react similarly to what is reported in Table 4, but employment would increase by around 30\% during a crisis, implying a $10 \%$ expansion of real GDP. Without additional ingredients, a wealth effect in labour supply is not consistent with the observed behaviour of employment and output during a twin crisis.

Fixed exchange rate regime What would a crisis look like in a fixed exchange rate economy where nominal rigidities impede the real depreciation? Following the discussion in Section 3.4.6, I simulate the same crisis using a model with monopolistic competition and pre-set prices in sector N. By construction, there is no real depreciation. The reversals of net exports and domestic demand have the same order of magnitude as in Table 4. In contrast, employment decreases by around $25 \%$ and real GDP by $20-25 \%$, that is, substantially more than in an economy able to depreciate the real exchange rate. Indeed, absent the decrease in prices of non-tradables, real wages experience a substantial decline, discouraging work. Real GDP declines because of both lower employment and lower capacity utilization. Because the price of capital goods (which depends on the price of non-tradables) stays high and investment expenditures are limited by the borrowing constraint, real investment declines more (by 68\%). These predictions are remarkably close to what a crisis country in a monetary union such as Greece has experienced. As of 2013, the peak-to-trough change was $-20 \%$ for employment, $-24 \%$ for GDP, and $-64 \%$ for fixed capital formation.

\section{FINAL REMARKS}

This article has built a two-sector model of financial fragility in a small open economy. The model was used to study the effect of an increase in financial openness on the sectoral structure of the economy and the financial structure of its non-tradable sector. In the short to medium run, larger capital inflows lead to a larger relative size of the non-tradable sector. This is in line with the documented behaviour of the sectoral structure during episodes of large capital inflows. At

20. In the context of sovereign debt, Arellano (2008) argues that output costs of defaults are important to account for empirically observed default probabilities.

21. The net export reversal is equal to $\Delta \mathrm{NX} / \mathrm{GDP}=\Delta(\mathrm{GDP}-\mathrm{DD}) / \mathrm{GDP}=\Delta \mathrm{GDP} / \mathrm{GDP}-\Delta \mathrm{DD} / \mathrm{GDP}$, where GDP and DD are measured in tradable goods. 
the same time, access to cheaper foreign loans leads firms to increase their leverage. The article shows how the evolution of these two factors tends to make crises more likely. This confirms the documented empirical evidence that large N-to-T ratios and large credit-to-GDP ratios are good predictors of twin crises.

A quantitative version of the model was brought to the data and suggests that decreases in the cost of foreign finance might have largely contributed to sectoral dynamics in several episodes of large capital inflows, including the recent crises in the euro area periphery.

On the methodological front, the article also suggests that a model with multiple equilibria can be a useful tool to quantitatively match the behaviour of macroeconomic variables during a large financial crisis such as Thailand in 1997.

In the model, crises are triggered by self-fulfilling purely expectational shocks but they could also be triggered by exogenous shocks on fundamentals which make the normal-time market clearing price disappear, e.g. a sudden stop that tightens borrowing constraints. ${ }^{22}$ This could explain why small shocks on fundamentals can have very large effects. It could also explain why two economies can react very differently to the same external shock: a financially fragile economy can jump to the crisis equilibrium, while other economies remain in the normal-time equilibrium, simply experiencing a slight real depreciation and a low decrease of investment. This is fully consistent with the way Argentina and Chile reacted to the 1998 sudden stop, as reported by Calvo and Talvi (2005): the Argentinean economy collapsed while Chile went through a mild recession.

As regards policy issues, financial fragility depends on two factors: (a) how large foreign currency liabilities are compared to domestic currency assets in firm balance sheets and (b) how large the non-tradable sector is compared to the tradable sector. While paying attention to mismatches in firm balance sheets is a lesson that is now widely agreed on, ${ }^{23}$ this article suggests that monitoring the evolution of the sectoral structure is also important. If policy makers are trying to prevent balance-of-payments crises, some intervention might be justified to mitigate the sectoral effects of capital inflows. A first way to do it would be to implement macroeconomic policies aimed at decreasing (or not increasing) the size of the financial transfer from abroad (for example by increasing domestic savings or limiting the extent of financial integration). Alternatively, policy makers could resort to sectoral interventions directly aimed at protecting the tradable sector from the effect of the real appreciation. This provides another justification for protecting or promoting the tradable sector to the ones already identified by the literature (increasing returns to scale, sunk costs to enter export markets, financial frictions, etc.) ${ }^{24}$ and suggests that there might be some complementarity between financial integration and industrial policy.

Acknowledgments. I would like to thank Philippe Bacchetta, Kenza Benhima, Robert Boyer, Craig Burnside, Ariel Burstein, Juan Carluccio, André Cartapanis, Pierre-Olivier Gourinchas, Pierre Jacquet, Ricardo Hausmann, Christian Hellwig, Claude Lopez, Philippe Martin, Benoît Mojon, Maurice Obstfeld, Jean-Paul Pollin, Julia Schmidt, Daniele Siena, Aaron Tornell, and three anonymous referees for their useful comments and advice, as well as participants to several seminars and conferences. Of course, all the remaining errors are my own.

\section{Supplementary Data}

Supplementary data are available at Review of Economic Studies online.

22. Calvo et al. (2004) argue that the sudden stop which followed the Russian crisis of 1998 led to episodes of large real depreciation in emerging countries.

23. See for example Allen et al. (2002).

24. See van Wijnbergen (1984), Hausmann and Rigobon (2002), Caballero and Lorenzoni (2007). 


\section{REFERENCES}

AGHION, P., BACCHETTA, P. and BANERJEE, A. (2004), "A Corporate Balance-Sheet Approach to Currency Crises", Journal of Economic Theory, 119, 6-30.

AGHION, P., BANERJEE, A. and PIKETTY, T. (1999), "Dualism and Macroeconomic Volatility”, The Quarterly Journal of Economics, 114, 1359-1397.

ALlEN, M., ROSENBERG, C. B., KELLER, C., SETSER, B. and ROUBINI, N. (2002), "A Balance Sheet Approach to Financial Crisis", (IMF Working Paper 02/210, International Monetary Fund, Policy Development and Review Department).

ANTRAS, P. and CABALlERO, R. (2009), "Trade and Capital Flows: A Financial Frictions Perspective”, Journal of Political Economy, 117, 701-744.

ARELLANO, C. (2008), "Default Risk and Income Fluctuations in Emerging Economies", The American Economic Review, 98, 690-712.

ATKESON, A. and KEHOE, P. (2005), "Modeling and Measuring Organization Capital”, Journal of Political Economy, 113, 1026-1053.

BENIGNO, G. and FORNARO, L. (2014), “The Financial Resource Curse”, Scandinavian Journal of Economics, 116, 58-86.

BERNANKE, B., GERTLER, M. and GILCHRIST, S. (1999), "The Financial Accelerator in a Quantitative Business Cycle Framework", in Taylor, J. B. and Woodford, M. (eds.), Handbook of Macroeconomics, (Vol. 1). Elsevier, 1341-1393.

BIANCHI, J. (2011), "Overborrowing and Systemic Externalities in the Business Cycle", The American Economic Review, 101, 3400-3426.

BRUNO, M. and SACHS, J. (1982), "Energy and Resource Allocation: ADynamic Model of the 'Dutch disease'”, Review of Economic Studies, 49, 845-859.

BURSTEIN, A., EICHENBAUM, M. and REBELO, S. (2005), "Large Devaluations and the Real Exchange Rate", Journal of Political Economy, 113, 742-784.

BURSTEIN, A. T., NEVES, J. C. and REBELO, S. (2003), "Distribution Costs and Real Exchange Rate Dynamics During Exchange-Rate-Based Stabilizations", Journal of Monetary Economics, 50, 1189-1214.

CABALLERO, R. J. and LORENZONI, G. (2007), "Persistent Appreciations and Overshooting: A Normative Analysis", (NBER Working Papers 13077, National Bureau of Economic Research).

CAGETTI, M. and DE NARDI, M. (2009), "Estate Taxation, Entrepreneurship, and Wealth”, American Economic Review, 99, 85-111.

CALVO, G. A., IZQUIERDO, A. and MEJÍA, L.-F. (2004), "On the Empirics of Sudden Stops: the Relevance of BalanceSheet Effects", (NBER Working Papers 10520, National Bureau of Economic Research).

CALVO, G. A. and TALVI, E. (2005), "Sudden Stop, Financial Factors and Economic Collapse in Latin America: Learning from Argentina and Chile", (NBER Working Papers 11153, National Bureau of Economic Research).

CALVO, G. A. and VEGH, C. A. (1999), "Inflation Stabilization and Bop Crises in Developing Countries", in Taylor, J. B. and Woodford, M. (eds.), Handbook of Macroeconomics, Vol. 1 of Handbook of Macroeconomics, Chapter 24. Elsevier, 1531-1614.

CHARI, V. V., KEHOE, P. J. and MCGRATTAN, E. R. (2005), “Sudden Stops and Output Drops”, The American Economic Review, 95, 381-387.

CHARI, V. V., KEHOE, P. J. and MCGRATTAN, E. R. (2007), "Business Cycle Accounting”, Econometrica, 75, 781-836.

COLE, H. L. and KEHOE, T. J. (2000), "Self-Fulfilling Debt Crises", Review of Economic Studies, 67, 91-116.

CORDEN, W. M. and NEARY, J. P. (1982), "Booming Sector and De-Industrialisation in a Small Open Economy", Economic Journal, 92, 825-848.

DE CORDOBA, G. F. and KEHOE, T. J. (2000), "Capital Flows and Real Exchange Rate Fluctuations Following Spain's Entry into the European Community", Journal of International Economics, 51(1), 49-78

EICHENGREEN, B. and HAUSMANN, R. (1999), "Exchange Rates and Financial Fragility", in New Challenges for Monetary Policy. (Kansas City: Federal Reserve Bank of Kansas City), 329-368.

GERTLER, M. and KARADI, P. (2011), “A Model of Unconventional Monetary Policy”, Journal of Monetary Economics, 58, 17-34.

HAUSMANN, R. and RIGOBON, R. (2002), “An Alternative Interpretation of the 'Resource Curse': Theory and Policy Implications", (NBER Working Papers 9424, National Bureau of Economic Research).

JONES, C. (2013), "Misallocation, Economic Growth, and Input-Output Economics", in Acemoglu, D., Arellano, M. and Dekel, E. (eds.), Advances in Economics and Econometrics, Vol. II. (Cambridge: Tenth World Congress, Cambridge University Press).

JUILLARD, M. (1996), "Dynare: A Program for the Resolution and Simulation of Dynamic Models with Forward Variables Through the Use of a Relaxation Algorithm", (Couverture Orange 9602, CEPREMAP).

KALANTZIS, Y. (2014), "Financial Fragility in Small Open Economies: Firm Balance Sheets and the Sectoral Structure", (Working papers 505, Banque de France).

KAMINSKY, G. and SCHMUKLER, S. (2003), "Short-Run Pain, Long-Run Gain: The Effects of Financial Liberalization”, (NBER Working Papers 9787, National Bureau of Economic Research).

KEHOE, P., MIDRIGAN, V. and PASTORINO, E. (2014), "Debt Constraints and Employment", (Mimeo). 
KRUGMAN, P. (1999), "Balance Sheets, the Transfer Problem, and Financial Crises", in Isard, P., Razin, A. and Rose, A. (eds.), International Finance and Financial Crises, Essays in Honor of Robert P. Flood. (Dordrecht: Kluwer).

MENDOZA, E. G. (2002), "Credit, Prices, and Crashes: Business Cycles with a Sudden Stop”, in Edwards, S. and Frankel, J. (eds.), Preventing Currency Crises in Emerging Markets, Chapter 7. (Chicago: University of Chicago Press).

MIAN, A. and SUFI, A. (2009), "The Consequences of Mortgage Credit Expansion: Evidence from the U.S. Mortgage Default Crisis", The Quarterly Journal of Economics, 124, 1449-1496.

MIAN, A. and SUFI, A. (2010), "Household Leverage and the Recession of 2007-09", IMF Economic Review, 58, 74-117.

MIAN, A. and SUFI, A. (2014), “What Explains the 2007-2009 Drop in Employment?”, (Research Paper 13-43, Chicago Booth).

NEUMEYER, P. and PERRI, F. (2005), “Business Cycles in Emerging Economies: The Role of Interest Rates”, Journal of Monetary Economics, 52, 345-380.

PHILIPPON, T. and MIDRIGAN, V. (2011), "Household Leverage and the Recession", (NBER Working Papers 16965, National Bureau of Economic Research).

REBELO, S. and VEGH, C. A. (1995), "Real Effects of Exchange-Rate-Based Stabilization: An Analysis of Competing Theories", in NBER Macroeconomics Annual 1995, Vol. 10. (Cambridge: MIT Press), 125-188.

SCHNEIDER, M. and TORNELL, A. (2004), "Balance Sheet Effects, Bailout Guarantees and Financial Crises", Review of Economic Studies, 71, 883-914.

TORNELL, A. and WESTERMANN, F. (2002), "Boom-Bust Cycles in Middle Income Countries: Facts and Explanation”, (NBER Working Papers 9219, National Bureau of Economic Research).

URIBE, M. (1997), "Exchange-Rate-Based Inflation Stabilization: The Initial Real Effects of Credible Plans", Journal of Monetary Economics, 39, 197-221.

VAN WIJNBERGEN, S. (1984), “The 'Dutch Disease': A Disease After All?”, Economic Journal, 94, 41-55. 